\title{
Are Victims Truly Worse Off in the Presence of Bystanders? Revisiting the Bystander Effect
}

\author{
26 July 2019 \\ Hanna Fromell ${ }^{\mathrm{a}}$, Daniele Nosenzo ${ }^{\mathrm{b}, \mathrm{c}}$, Trudy Owens $^{\mathrm{c}}$ and Fabio Tufano ${ }^{\mathrm{c}}$
}

\begin{abstract}
:
Previous studies have shown that individuals are less likely to help a person in need when there are "bystanders" present who can also offer help. We designed an experiment to re-examine this "bystander effect" using modified dictator games. We find lower giving rates in the presence of bystanders, confirming the existence of a bystander effect. However, we also show that the recipient's welfare is greater when bystanders are present, challenging the usual interpretation that the bystander effect is due to an erosion of prosocial values and social norms.
\end{abstract}

Keywords: bystander effect, bystander dilemma, diffusion of responsibility, dictator game, social norms.

JEL Classification Numbers: C92, D64

Acknowledgements: We thank Pol Campos-Mercade, two anonymous reviewers, and participants at the 2015 CeDEx-CREED-CBESS Meeting for helpful comments. This work was supported by the British Academy \& Leverhulme Trust (SG140436) and by the University of Nottingham.

\footnotetext{
${ }^{\text {a }}$ Department of Economics, Econometrics, and Finance, University of Groningen.

${ }^{b}$ Luxembourg Institute of Socio-Economic Research (LISER).

${ }^{c}$ School of Economics, University of Nottingham.
} 


\section{Introduction}

In many situations, the creation of beneficial outcomes for others and/or society depends on the actions of a single individual. Examples include cleaning a communal area in shared residences, volunteering for a social activity or event, and many types of situations in which one person is in need of help from another individual. There is a large experimental literature supporting the idea that, in such situations, the presence of multiple individuals who can potentially generate the beneficial outcome, is detrimental. This phenomenon, which has been labelled the "bystander effect", was first documented in the seminal paper by Darley and Latané (1968). Participants in their experiment witnessed a confederate staging an epilepsy seizure. Darley and Latané (1968) found that subjects who believed that other participants were also witnessing the seizure were less likely to react to the incident and call for help compared to those who believed they were alone. A large literature in economics and psychology has developed since this study confirming that the presence of multiple potential "helpers" lowers the rate at which each single individual is willing to help (e.g., Darley and Latané, 1968; Latané and Darley, 1970; Cryder and Loewenstein, 2012; see Fischer et al., 2011 for a review). ${ }^{1}$

At the heart of this phenomenon lies the existence of strategic interdependence between the actions of the multiple individuals who can potentially generate the beneficial outcome: only one person is needed to produce this outcome, and yet everyone can volunteer to do so. This interdependence between bystanders' actions introduces different possible motivations that may reduce each individual's willingness to benefit others when this is costly for the individual. For instance, if one bystander believes that someone else may actually help, she may be tempted to free-ride. If she instead believes that no one else will help, then the blame for not helping can be diffused among all bystanders, which may lower the psychological cost of guilt (Latané and Nida, 1981; Dana, Weber, and Kuang, 2007). Both mechanisms may affect the social norm to help those in need, as suggested by

\footnotetext{
${ }^{1}$ The bystander effect has been studied in various settings in the economics literature, including dictator games (e.g., Dana, Weber, and Kuang, 2007; Panchanathan, Frankenhuis, and Silk 2013), sender-receiver games (e.g., Behnk, Hao, and Reuben 2017), lying games (e.g. Weisel and Shalvi 2015; Barr and Michailidou 2017), and market games (e.g., Falk and Szech 2013; Bartling, Weber, and Yao 2015).
} 
Darley and Latané (1968). Thus, the conventional wisdom is that the presence of bystanders "erodes" prosocial values and social norms.

In this paper we report an experiment that challenges this relatively pessimistic interpretation of the bystander effect. Much of the focus of this literature has been on the individual probability to offer help (the so-called "helping rate"). However, we conjecture that the mere fall in the helping rate is not necessarily a good measure to gauge whether the presence of bystanders results in an erosion of prosocial values or indeed harms the victim. We identify two reasons why this may be the case. First, when several bystanders can help, the helping rate would have to fall considerably for the victim to be less likely to receive help by at least one of them. Consider the case where the helping rate is $50 \%$ when there is only one bystander, implying that the recipient receives help with 50\% probability. If the number of bystanders triples, the recipient would be less likely to receive help by at least one of them only if the helping rate falls below $21 \%$. Yet, a review by Latané and Nida (1981) shows that the reduction in helping rates in the presence of bystanders observed in experimental studies is typically small. Thus, it is unclear whether the victim is actually harmed by the presence of bystanders. ${ }^{2}$

Second, we notice that, in practice, individuals differ in their ability to help others, and so whether or not a drop in the helping rate is detrimental for the victim depends on whose help (the most or least able individuals) is crowded out in the presence of bystanders. ${ }^{3}$ If the individuals who abstain from helping are those who are least able to help, then the average quality of help (conditional on help being offered) may actually increase despite a fall in the helping rate, and the victim may potentially be better off. In this sense, the very reason why a low-ability individual might abstain from providing help in the presence of

\footnotetext{
${ }^{2}$ See Campos-Mercade (2017) on this point. Moreover, note that this is also the case in the volunteer's dilemma (VOD). In the VOD, a group of individuals can volunteer to produce a public good. A dilemma arises since volunteering is in each individual's interest if no-one else volunteers, but volunteering when at least one other individual does so only results in a deduction of money with no further increase of the public good. These studies typically show that, although the individual propensity to volunteer decreases with group size, the probability that at least one group member volunteers (and so the public good is provided) does not (Franzen, 1995; Weesie and Franzen, 1998; Goeree and Holt, 2005; Goeree, Holt, and Smith, 2017).

${ }^{3}$ In many real life situations where an individual needs help (e.g., medical emergencies or situations involving crime), the outcome for the victim crucially depends not only on whether someone is willing to help, but also on the extent to which the person intervening has the necessary skills and resources to help (e.g., they may or may not be a medical doctor or an off-duty policeman).
} 
bystanders could be genuine care for the person in need, rather than an erosion of prosocial values and social norms. However, if the high-ability individuals are those who largely abstain from helping, then the fall in the helping rate may lead to a fall in the quality of help provided, making the victim worse off. To the best of our knowledge, none of the previous studies on the bystander effect allow for an analysis of the extent or quality of help that is received by the victim.

Taken together, these two arguments challenge the conventional interpretation of the bystander effect: the mere fact that the helping rate falls in the presence of bystanders may not necessarily imply a reduction in the welfare of the victim, or be driven by mechanisms that imply an erosion of prosocial values and social norms. Despite a drop in the helping rate, the victim may not be less likely to receive help from at least one bystander, and the quality of the help received may actually be higher; either of these effects may suffice to increase the victim's expected welfare. This also opens the possibility that the observed reduction in the helping rate may not necessarily be driven by a weakening of prosocial values and social norms.

In Section 2, we describe an experiment designed to probe this conjecture. Our experimental paradigm is based on a dictator game modified to capture the essence of the bystander dilemma. In our "Bystander" treatment, a group of seven dictators is matched with one recipient. Dictators simultaneously choose whether or not to give money to the recipient and, if they choose to give, how much (an amount between $£ 1$ and $£ 10$ ). The rule for determining the earnings of the recipient is as follows: if at least one dictator gives, the recipient receives positive earnings with certainty; among the dictators who choose to give, one is selected at random and their choice is implemented. If all dictators choose not to give, then the recipient receives zero earnings.

The Bystander treatment captures the essence of the bystander dilemma by introducing a strategic interdependence among the seven dictators. The earnings of the recipient depend on the simultaneous decisions of all dictators, and how the choice of one dictator affects the recipient's earnings depends on the choices of the other six dictators. For instance, if a dictator chooses not to give, this may either result in zero earnings for the recipient (if all other six dictators also do not give) or not (if at least one other dictator 
gives). In this setting, the bystander effect can thus arise through two mechanisms that have been frequently mentioned in the literature as an explanation of the effect. First, dictators may expect others to give and therefore be tempted to free-ride on the benevolence of other dictators. Second, a "diffusion of responsibility" could occur whereby dictators abstain from giving because they believe that all other dictators are also abstaining, which makes everyone equally responsible for the bad outcome for the recipient.

We compare the Bystander treatment with a "Control" treatment in which there is no strategic interdependence between the dictators. As in the Bystander treatment, also in Control we match seven dictators with one recipient. However, differently from Bystander, the earnings of the recipient are computed using the choice of one, randomly chosen, dictator (regardless of whether they decided to give or not). Thus, although the number of dictators per group is the same in the Control and Bystander treatments (so as to control for possible effects related to the mere presence of other individuals), free-riding and diffusion of responsibility, which are at the heart of the bystander effect, cannot play a role in Control. This is because in Control the impact of each dictator's decision on the recipient's earnings is independent from the decisions of the other dictators in the group. ${ }^{4}$

Importantly, in both treatments, dictators choose not only whether to give, but also how much. This allows to verify whether the presence of bystanders has an effect on the "quality" of giving. As explained above, it is not clear whether the presence of bystanders affects positively or negatively the quality of help provided and the recipient's expected welfare. In our experiment, recipients will be worse off in expectations in the Bystander treatment only if the average amount given, conditional on giving, falls below the average amount given in the Control treatment. Otherwise, the recipient will not be worse off, and may in fact be better off in Bystander than in Control, even if the proportion of dictators who give falls.

\footnotetext{
${ }^{4}$ Since our design holds constant the number of dictators in the decision situation across the Control and Bystander treatments, we cannot capture the differential effect of "being alone" in the decision situation as opposed to "being in the presence of others". To the extent that the "bystander effect" is due - at least in part - to this mechanism, our design is not well suited to study it. We further discuss this limitation of our design in section 2 below.
} 
In Section 3, we report our data analysis, which focuses on three aspects of our treatment comparison. ${ }^{5}$ First, we focus on the proportion of dictators who choose to give a positive amount to the recipient (what we call the "giving rate"). We find a marginally significant (at the 10\% level) reduction in the giving rate in the Bystander treatment compared to Control (33\% compared to 44\%). This reproduces the commonly observed bystander effect whereby, in the presence of other individuals who can affect the welfare of a recipient, the willingness of each single individual to give is reduced.

Second, we compare the likelihood that the recipient will receive positive earnings across the two treatments. As explained above, this can be lower in Bystander than in Control, but only if the giving rate falls by a large amount so as to contrast the positive effect of having more individuals who are in principle "able" to give. We find that recipients are in fact significantly more likely to receive positive earnings in Bystander than in Control. Thus, if one focuses on this specific aspect of the recipient's welfare, the recipient is actually better off in the presence of bystanders.

Third, we compare the recipient's expected earnings across the two treatments. We find that these are significantly higher in the Bystander treatment compared to Control. The reason why this is the case is that, despite the fall in the giving rate, the average amount given, conditional on giving, is not significantly different between the two treatments. Thus, the "quality" of giving is not crowded out by the presence of bystanders. This, combined with the fact that the giving rate only falls by little in Bystander, implies that the recipient is better off in expectations in the presence of bystanders.

In addition to the above treatment comparisons, we also report an exploratory analysis of the motivational aspects behind dictators' behaviour by using an incentivized measure of their beliefs about the behaviour of other dictators as well as results from a second experiment in which we measure the effect of the Bystander treatment on the social norm of giving using the norm elicitation task developed by Krupka and Weber (2013). We

\footnotetext{
${ }^{5}$ Both treatments were run across two different conditions, in which subjects were either anonymous to one another, or identified by their name initials. We found no differences in any of the experimental outcomes across the two anonymity conditions and so we pool data across these conditions. We discuss the lack of effect of our anonymity manipulation in Section 3 and present a disaggregated analysis of data in Appendix A.
} 
find little evidence that free-riding or diffusion-of-responsibility considerations that weaken social norms are at play in our experiment.

In Section 4, we discuss our results and conclusions. Although in our experiment we do observe a reduction in the individual willingness to give to others in the presence of bystanders, we find that overall this does not translate in lower expected earnings for the recipient. Indeed, recipients in our experiment are on average better off in the Bystander treatment than in Control. Our results call into question the conventional and relatively pessimistic interpretation of the bystander effect proposed in the previous literature.

\section{Experimental Design}

\subsection{Experimental Game and Treatments}

Our experiment is based on a modified version of the dictator game. Subjects were randomly divided into groups of eight and then randomly assigned a role: one subject was assigned the role of recipient (called "Participant A" in the experiment) and seven subjects the role of dictator ("Participant B"). Dictators received an endowment of $£ 10$, while the recipient's endowment was $£ 0$. Recipients had no decision to make in the experiment. Each of the seven dictators in a group had to simultaneously choose whether or not to transfer a positive amount to the recipient. If they decided to transfer a positive amount, they had to specify the exact amount by choosing an integer between $£ 1$ and $£ 10$. Although all seven dictators in each group were asked to make this choice, at most one dictator in each group would have their choice implemented. Which choice was implemented was randomly determined after all dictators had made their decision so that all choices were elicited in an incentive-compatible way. Dictators who were not selected kept their initial endowment.

The Control and Bystander treatments differ in the rule used to determine which of the seven dictators' choices was selected to be implemented. In our Control treatment, each dictator had the same probability (equal to 1/7) of being selected and having their choice implemented, regardless of their own choice or the choices of the other dictators in their group. In the Bystander treatment, the probability that a dictator was selected depended both on their own choice and on the choices of other dictators in their group. If a dictator decided not to give, the probability of being selected was either zero (if at least one other 
dictator gave) or 1/7 (if none of the other dictators gave). If a dictator decided instead to give, the probability of being selected was equal to $1 / n^{+}$, where $n^{+}$is the number of dictators choosing to give.

Our Bystander treatment introduces a strategic interdependence between dictators' actions that allows for the presence of two key phenomena typically present in the bystander dilemma (Dana et al., 2012). First, it introduces free-rider incentives for dictators who are willing to give money to the recipient, but still prefer that someone else bears the cost of giving. For instance, if at least one other dictator gives, these dictators can withdraw their giving without causing the recipient to earn nothing. Second, the Bystander treatment allows for a diffusion of responsibility among dictators since the blame of a bad outcome for the recipient can be shared among all the dictators in the group. For example, if the recipient ends up earning nothing, the blame falls equally on all dictators in the group: it would have been enough that any of them had chosen to give for the recipient to receive positive earnings. ${ }^{6}$

This strategic interdependence between dictators' actions is not present in our Control treatment. Free-riding on other dictators is not possible since each dictator's choice has a $1 / 7$ probability of being implemented, regardless of what they or others do. For the same reason, there cannot be any diffusion of responsibility since the earnings of the recipient depend entirely on the dictator whose choice is selected to be implemented.

Note that our design keeps constant across treatments the number of dictators who are matched with the recipient. This is because we wanted to be able to isolate the "bystander effect" that is due to the strategic interdependence between dictators' actions rather than to the mere presence of bystanders. However, a potential drawback of this design choice is that, if the "bystander effect" is in part due to the behavioural difference between the psychology of "being alone" and the psychology of "being in the presence of others", then our experiment cannot capture this. Therefore, the results of our treatment comparisons should be interpreted holding this caveat in mind.

\footnotetext{
${ }^{6}$ Note that because choices are made simultaneously we can exclude social comparison effects such as those proposed by Latané and Nida (1981), Latané and Dabbs Jr (1975), and Bicchieri (2006), whereby individuals may imitate each other's inaction.
} 
Our treatments also keep constant the procedures to elicit dictators' choices. In particular, in both treatments dictators were asked to make a choice before knowing whether their choice would be implemented. In the Bystander treatment, this reflects the underlying structure of the simultaneous game. In the Control treatment dictators' choices are independent from one another so our procedure is essentially akin to using the strategy method (Selten, 1967). ${ }^{7}$

In our treatment comparisons, we are mainly interested in studying the relation between dictators' giving and recipient's earnings across the two treatments. As discussed above, a reduction in the giving rate (i.e., the proportion of dictators who choose to give, used as an estimate of an individual's propensity to give) in the Bystander treatment may not necessarily imply that the recipient is worse off than in Control. To see this note that in the Bystander treatment the recipient's earnings are either equal to zero (if all dictators in a group do not give) or (if at least one dictator chooses to give) to the average amount given by dictators who make a positive transfer, denoted $\bar{t}_{B}{ }^{+}$. The probability that at least one dictator gives is equal to $1-\left(1-p_{B}\right)^{n}$ where $p_{B}$ is the giving rate in Bystander and $n$ is the number of dictators in the group. ${ }^{8}$ Thus, the recipient's expected earnings in Bystander are $\left[1-\left(1-p_{B}\right)^{n}\right] \bar{t}_{B}{ }^{+}$. In the Control treatment, the recipient's expected earnings simply equal the average amount given by all dictators, denoted $\bar{t}_{C}$. Note that this can be rewritten as $p_{C} \bar{t}_{C}{ }^{+}$, i.e., the product between the giving rate and the average amount given by dictators who make a positive transfer in Control. The recipient's expected earnings are thus lower in Bystander if:

$$
\left[1-\left(1-p_{B}\right)^{n}\right] \bar{t}_{B}^{+}<p_{C} \bar{t}_{C}^{+}
$$

This expression implies that a fall in the giving rate in Bystander might not necessarily translate into a reduction in the recipient's expected earnings. First, consider the case where the average amount given (conditional on giving) is the same across the two treatments,

\footnotetext{
${ }^{7}$ Note that this implies that, in both treatments, dictators' actions are implemented probabilistically. This may have an impact per se on the propensity to give since dictators' attitudes towards risk may play a role on their giving decisions. Indeed, Cettolin et al. (2017) show that risk preferences matter in allocation games where the final amount transferred by an allocator to a recipient is determined probabilistically.

${ }^{8}$ Here we are assuming that each dictator has a propensity to give a positive amount to the recipient equal to $p_{B}$, and thus the probability that in a group of $n$ dictators, all of them give nothing is equal to $\left(1-p_{B}\right)^{n}$.
} 
$\bar{t}_{B}{ }^{+}=\bar{t}_{C}{ }^{+}$. Then the recipient will be worse off in expectations in the Bystander treatment only if the giving rate in Bystander falls below $1-\left(1-p_{C}\right)^{1 / n}$. In our treatment, where $n=7$, this implies a substantial drop in the giving rate. For example, if the giving rate in Control is 50\%, the giving rate in Bystander would have to fall below 9.4\% for the recipient to be worse off in expectations. Note also that the same condition holds for the probability that the recipient receives positive earnings. Thus, according to this measure of recipient's welfare (whether or not the recipient ends up with zero earnings), a substantial drop in the propensity to give is needed to make the recipient worse off. ${ }^{9}$

Moreover, whether or not the recipient will be worse off also depends on how the average amount given (conditional on giving) compares between the two treatments. This is a feature that previous studies of the bystander effect could not analyse because of their focus on binary decision environments where subjects could only either help/give or not. In contrast, we are interested in studying how the presence of bystanders affects the "quality" of help provided and not just whether help is provided. Thus, in our design dictators can transfer any integer amount between $£ 1$ and $£ 10$ to the recipient, if they decide to give.

The average amount given (conditional on giving) may fall in Bystander relative to Control if there is an erosion of prosocial values and social norms in the presence of bystanders. For example, dictators may reduce the amount given in order to free-ride on other dictators. Similarly, dictators may give less due to a diffusion of responsibility, if they believe that others also give little and feel that giving small amounts is more acceptable if everyone else does so.

On the other hand, there is a possibility that the presence of bystanders may increase the average amount given (conditional on giving). This is because in the Bystander treatment dictators may prefer giving nothing instead of a small amount in order to increase the expected earnings of the recipient. To see this, note that in the Control treatment the recipient's expected earnings increase monotonically in the amount transferred by a dictator. In contrast, a crucial feature of our Bystander treatment is that a dictator $i$ affects the

\footnotetext{
${ }^{9}$ While in our experiment we keep the group size constant, it may be interesting to study how variations in group size induce differences in giving rates and in the recipient's welfare. In particular, there may be nonmonotonicities in the effect of $n$ on giving, which are not captured by the simple calculation shown above. See Campos-Mercade (2017) for a recent experiment on the relation between group size and bystander effect.
} 
recipient's expected earnings positively only if they make a transfer that is greater than the average positive transfer of the other dictators in the group. Otherwise, the recipient would be better off if the dictator had abstained from giving. For example, a dictator would increase the recipient earnings by choosing not to give compared to giving $£ 1$ if the average positive transfer of all other dictators is greater than $£ 1$. This mechanism would essentially "crowd-out" the giving of those who are prepared to give little, letting instead "large donors" volunteer to help the recipient. Thus, the overall impact on the recipient's welfare may be positive.

\subsection{Beliefs and Norms Elicitation}

The previous discussion suggests that a reduction in the giving rate in the Bystander treatment may not necessarily be driven by an erosion of prosocial values and social norms due to free-riding incentives or diffusion of responsibility. In order to gain a better understanding of subjects' motivations in the experiment, we elicited dictators' beliefs about other dictators' giving and the recipient's earnings in their group.

The belief elicitation task was identical across treatments and was implemented after subjects had made their choices, but before they learned the outcomes of the dictator game. Dictators answered nine questions in total. In seven of these questions, each dictator was asked to guess how many of the other six dictators had chosen not to transfer, transfer $£ 1$, $£ 2, £ 3, £ 4, £ 5$, and $£ 6$ or more to the recipient. ${ }^{10}$ In the other two questions, dictators' were asked about their beliefs about the recipient's final earnings as well as their second-order beliefs about the recipient's beliefs of his/her own earnings. All questions were incentivised by paying dictators $£ 1$ for giving the correct answer to one randomly selected question. ${ }^{11}$

To further probe the motivations behind dictator's giving in the two treatments, we also conducted a norm elicitation experiment to study how the presence of bystanders

\footnotetext{
${ }^{10}$ Since transfers above the equal split (i.e., in excess of $£ 5$ ) are extremely rare in dictator games, we grouped the options of transferring $£ 6, £ 7, £ 8, £ 9$, and $£ 10$ into one question. This reduced the number of questions that subjects had to answer and made the task more manageable. Only 5 of the 252 dictators thought that another dictator had chosen to transfer between $£ 6$ and $£ 10$.

${ }^{11}$ We also measured recipients' beliefs about how much the dictators in their group had chosen to transfer to them, their own earnings from the game, and how much the dictators in their group expected the recipient to earn on average. The recipient's questions were not incentivised so that dictators knew that recipients would earn $£ 0$ from the experiment if they did not receive anything in the dictator game.
} 
affected the social norms of giving in our setting. This experiment was conducted with a new group of subjects who had not taken part in the main experiment and used the norm elicitation method introduced by Krupka and Weber (2013). Subjects read a vignette that described the dictator game, including a description of each of the possible actions dictators could take. Approximately half of the subjects read a description of the game played in the Bystander treatment, while others read a description of the Control treatment. After reading the vignette, subjects were asked to rate the social appropriateness of the actions available to the dictator, using a 6-point scale ranging from "very socially inappropriate" to "very socially appropriate". Subjects rated the actions independently but were given monetary incentives to coordinate their ratings with those of other subjects: at the end of the experiment, subjects were randomly matched into pairs and one of the rated actions was selected at random. If the subjects in the pair had rated the selected action in the same way, they both earned $£ 8$; otherwise they both earned $£ 0 .{ }^{12}$

Note that our elicitation of norms involves "third-parties", i.e. subjects who did not themselves play the dictator game in either the Bystander or Control treatment. This is standard procedure in experiments using the Krupka-Weber norm-elicitation method. The use of such "between-subject" design is justified on the grounds that the norms that the procedure aims to elicit are "social" in the sense of being shared understandings of what is appropriate or inappropriate among a reference group of individuals (in our case, the reference group may be defined as the group of participants in experiments at our institution). Since both the behavioural and norm-elicitation experiments sample from the same population, it is reasonable to assume that the two samples hold the same social norms regarding the target behaviour elicited by the procedure. ${ }^{13}$

\footnotetext{
${ }^{12}$ These procedures follow Krupka, Leider, and Jiang (2016). The six possible ratings were: "very socially inappropriate", "socially inappropriate", "somewhat socially inappropriate", "somewhat socially appropriate", "socially appropriate", and "very socially appropriate".

${ }^{13}$ It is of course also possible to elicit norms using a "within-subject" design, where norms are elicited from the same subjects whose behaviour is observed in the experiment (e.g., Barr et al., 2018 for a study using norms elicited in a within-subject designs). However, a potential caveat to keep in mind is that, as discussed by D'Adda et al. (2016), there may be spillovers between the norm-elicitation task and the behavioural task in within-subject designs.
} 


\subsection{Procedures}

The experiments were programmed in z-Tree (Fischbacher, 2007) and were run at the computerized laboratory of the University of Nottingham with students recruited through the online recruitment system ORSEE (Greiner, 2015). The main experiment was run with 288 subjects (252 dictators), evenly divided between Bystander and Control treatments. ${ }^{14}$ We recruited another 122 subjects for the norm elicitation experiment (62 in Bystander and 60 in Control). Average earnings were $£ 9.3$ in the main experiment (ranging from $£ 0$ to $£ 11$ ) and $£ 7.4$ in the norm elicitation experiment (ranging from $£ 4$ to $£ 12$ ). ${ }^{15}$ All sessions finished within one hour. Instructions for the experiments are reproduced in Appendix B.

\section{Results}

The Bystander and Control treatments were run under two conditions. In one condition subjects remained fully anonymous to one another throughout the experiment, whereas in the other condition they were partially identified by the first letters of their forename and surname. This manipulation aimed to explore whether a reduction in anonymity moderates the bystander effect. We found no effect of a reduction in anonymity on giving or norms of giving and so in the remainder of the paper we pool the data from the two conditions. ${ }^{16} \mathrm{We}$ further discuss this manipulation in Appendix A, where we also present a replication of the analysis reported in the paper disaggregated by the two conditions.

\footnotetext{
14 Thus, our treatments are administered using a between-subject design. An interesting avenue for further research could be to design a within-subject experiment to study the individual-level determinants of the bystander effect.

${ }^{15}$ There was no show-up fee for subjects in the main experiment because we wanted recipients to receive positive earnings only if dictators gave to them. A $£ 4$ show-up fee was paid in the norm elicitation experiment. ${ }^{16}$ Our manipulation to reduce anonymity is fairly subtle and prevents full identification since subjects only learn each other's name initials. Thus, the null result may be interpreted as a failure of the manipulation to reduce anonymity across treatments. On the other hand, previous experiments that have used stronger manipulations to reduce anonymity (e.g., revealing family names; or having decisions announced in public) have produced mixed results (see, e.g., Dufwenberg and Muren, 2006; Charness and Gneezy, 2008), which may also explain why we do not find an effect in our experiment.
} 


\subsection{Giving Behaviour and Recipient Earnings}

Figure 1 shows the distribution of amounts transferred by the dictators in the two treatments and Table 1 summarizes the main outcomes of the experiment.

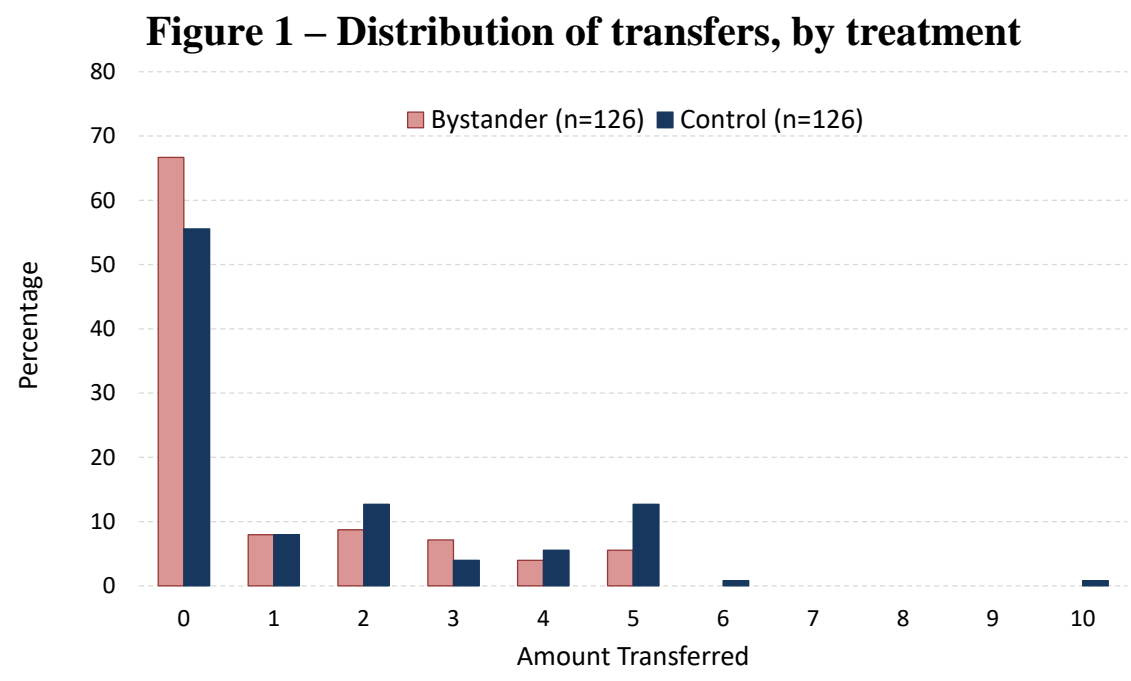

Table 1 - Main outcomes of the experiment, by treatment

\begin{tabular}{l|cc}
\hline \hline & Bystander & Control \\
\hline Giving rate (\% of dictators who chose to give) & $33 \%$ & $44 \%$ \\
Average amount given & $0.90(1.51)$ & $1.44(2.01)$ \\
Average amount given, conditional on giving & $2.71(1.40)$ & $3.23(1.82)$ \\
Probability that recipient receives positive earnings & $94 \%$ & $44 \%$ \\
Recipient's expected earnings & 2.55 & 1.44 \\
\hline \hline
\end{tabular}

Note: Standard deviations in parentheses. In Bystander the probability that the recipient receives positive earnings is computed as $1-\left(1-p_{B}\right)^{n}$, where $p_{B}$ is the giving rate and $n=7$. In Control it is equal to the giving rate. In Bystander the recipient's expected earnings are computed as $\left[1-\left(1-p_{B}\right)^{n}\right] \bar{t}_{B}{ }^{+}$where $\bar{t}_{B}{ }^{+}$ is the average amount given, conditional on giving. In Control the recipient's expected earnings are equal to the average amount given.

The proportion of dictators who gave a positive amount to the recipient, i.e. the giving rate, is lower in Bystander (33\%) than in Control (44\%). This difference is marginally 
significant at the $10 \%$ level $\left(\chi^{2}(1)=3.27, \mathrm{p}=0.07\right) .{ }^{17}$ This result is in line with the findings from the previous literature on the bystander effect and confirms that the presence of bystanders reduces each individual's willingness to give. The average amount given is also lower in Bystander (0.90) than in Control (1.44), and the difference is significant at the $5 \%$ level (Fisher's randomization test, $\mathrm{p}=0.02){ }^{18}$

To investigate the effect of the presence of bystanders on the recipient's welfare, we start by comparing the probability that the recipient receives positive earnings in the two treatments. This equals the probability that a randomly selected dictator chooses to give in the Control treatment, and the probability that at least one out of seven dictators give in the Bystander treatment. Assuming that the giving rate is an estimate of an individual's propensity to give, these two probabilities can be derived from the giving rates observed in the experiment, as discussed in the previous section. The probability of receiving positive earnings is much higher in the Bystander treatment (94\%) compared to the Control treatment (44\%). We can also consider the realised randomization of dictators into different groups and compute the probability of positive recipient earnings in each group, given the choices of the seven dictators in that group. We confirm a similar difference across treatments: the probability for the recipient to receive positive earnings is significantly higher in Bystander compared to Control ( $89 \%$ vs. 44\%, Fisher's randomization test, $\mathrm{p}<$ 0.01). ${ }^{19}$ Thus, the positive effect of the increase in the number of individuals who can give outweighs the negative effect of the drop in the giving rate, leaving the recipient better off in terms of the probability of receiving positive earnings.

We next analyse the effect of treatment on the recipient's expected earnings. These depend on both the probability of receiving positive earnings and the average amount given, conditional on giving. We find that there is no significant difference in the average amount given conditional on giving between the Bystander treatment and Control treatment (2.71

\footnotetext{
${ }^{17}$ The tests reported in the paper are two-sided and treat data from each subject as an independent observation, unless indicated otherwise. Thus, in the main experiment the tests are based on 126 observations per treatment. ${ }^{18}$ See Moir (1998) for a discussion of the randomization test.

${ }^{19}$ This test treats each group as an independent observation and is thus based on 18 observations per treatment.
} 
vs 3.23, Fisher's randomization test, $\mathrm{p}=0.14){ }^{20}$ This means that we find no significant evidence of a crowding out of the "quality" of giving in the presence of bystanders. The fact that the average amount given conditional on giving is not different across treatments, combined with the fact that the recipient is more likely to receive positive earnings in Bystander than in Control, implies that the recipient's expected earnings are in fact higher in the Bystander treatment relative to Control (2.55 vs. 1.44). To test the significance of this difference, we consider the realized randomization of dictators into different groups and compute the recipient's expected earnings in each group, given the choices of the seven dictators in that group. We find that the recipient's expected earnings are significantly higher in Bystander than in Control (2.42 vs. 1.44, Fisher's randomization test, $\mathrm{p}=0.01$ ). ${ }^{21}$

\subsection{Beliefs and Norms across Treatments}

In this section we present an exploratory analysis of the motivations underlying the behaviour observed in the main experiment. We are particularly interested in understanding whether the fall in giving rate and average amount given observed in the Bystander treatment are to be interpreted as due to an erosion of prosocial values and social norms. The fact that, as we have seen in the previous section, the recipient's welfare is actually higher in Bystander than Control suggests that this may not be the case. Our analysis of dictators' beliefs and norms reinforces this notion.

As discussed above, there are two mechanisms that could lead to a fall in the giving rate in the Bystander treatment. On the one hand, in the presence of bystanders dictators may be tempted to free-ride on others and thus reduce their own giving. This mechanism implies that dictators who do not give should hold high beliefs about others' giving, hence suggesting a negative correlation between dictators' beliefs and whether they choose to give or not in the Bystander treatment. However, the beliefs data show that this is not the case. Compared to dictators who give a positive amount, dictators who do not give believe that significantly fewer others in their group give and that the average amount given is

\footnotetext{
20 This test focuses only on dictators who gave a non-zero amount and is thus based on 42 observations in Bystander and 56 observations in Control.

${ }^{21}$ This test treats each group as an independent observation and is thus based on 18 observations per treatment.
} 
significantly smaller (Fisher's randomization tests, both $\mathrm{p}<0.01$ ). ${ }^{22}$ More generally, a Tobit regression of own giving on a dictator's belief of the average amount given by others in their group shows a strong positive correlation between the two measures (coefficient 2.19, $\mathrm{t}=5.04, \mathrm{p}<0.01)$.

The second mechanism proposes that the presence of bystanders triggers a diffusion of responsibility whereby giving little is more acceptable when one believes others in the group are also giving little, since the responsibility for the low earnings of the recipient can be shared with others. The positive correlation between dictator's own giving and beliefs of others' giving is consistent with this mechanism. ${ }^{23}$ However, if reduced giving indeed stems from a perception that it is more socially acceptable to avoid giving in the presence of other, then one would also expect to observe a shift in the social appropriateness of giving low amounts in the Bystander treatment compared to Control. The data collected in the norms elicitation experiment do not support this.

Figure 2 shows, for each treatment, the average social appropriateness ratings elicited in the norm elicitation experiment for each of the actions available to the dictator. ${ }^{24}$ In both treatments, transferring nothing to the recipient was viewed as the least socially appropriate action. The level of social appropriateness gradually increases with the amount given by the dictator, up to the action of transferring $£ 5$ (which represents an equal split between the dictator and the recipient) and decreases slightly thereafter. This general pattern of appropriateness ratings closely resembles that typically obtained in standard two-player dictator games (e.g., Krupka and Weber, 2013; Erkut, Nosenzo, and Sefton, 2015).

\footnotetext{
${ }^{22} \mathrm{We}$ can reconstruct a belief of the amount given by others for almost all dictators in the sample. Five dictators believed that one other dictator gave $£ 6$ or more to the recipient. For these dictators, we do not know the exact amount that they believed others transferred to the recipient. For simplicity, we arbitrarily set this value equal to $£ 6$. The results are unchanged if we instead drop these five dictators from the analysis.

${ }^{23}$ This positive correlation is also consistent with a "false consensus effect" whereby individuals report beliefs that others act in similar ways as themselves (Ross, Greene, and House, 1977; Engelmann and Strobel, 2000; Engelmann and Strobel, 2012).

${ }^{24}$ Following Krupka and Weber (2013), we assigned evenly-spaced values of -1 for the rating "very socially inappropriate", -0.6 for the rating "socially inappropriate", -0.2 for the rating "somewhat socially inappropriate", 0.2 for the rating "somewhat socially appropriate", 0.6 for the rating "socially appropriate", and 1 for the rating "very socially appropriate". We report the full distributions of appropriateness ratings in Appendix C.
} 
Importantly, we find only small differences in the way the actions are rated across the two treatments. In fact, a series of Fisher's randomization tests performed for each of the 11 possible dictator's actions reveals no significant differences between appropriateness ratings in the Bystander and Control treatments (in all cases the p-values exceed the $10 \%$ threshold). ${ }^{25}$ Thus, giving little is not viewed as more appropriate in the presence of bystanders, as a diffusion of responsibility mechanism would suggest. More generally, we do not find evidence in favour of the conjecture proposed by Darley and Latané (1968) that social norms are more accepting towards the action of not giving when individuals are in the presence of bystanders.

Figure 2 - Social appropriateness ratings, by treatment

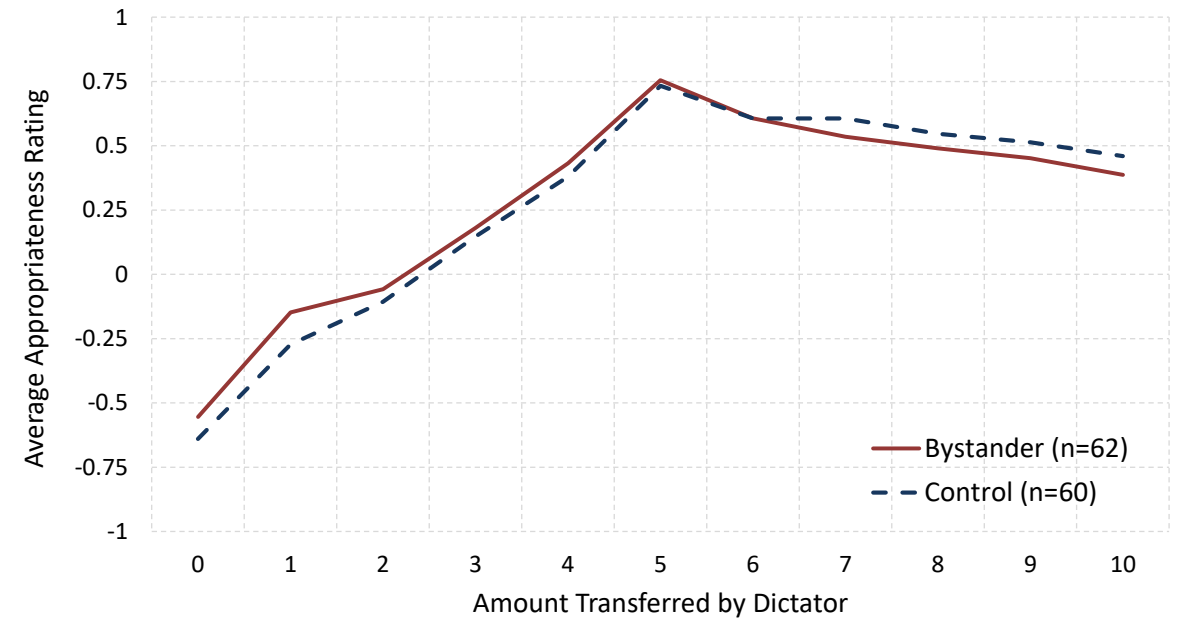

\section{Conclusions}

We designed a dictator game experiment to re-examine the interpretation of the "bystander effect" made in the previous literature. The bystander effect occurs when an individual witnessing a person in need of help is less likely to offer help when other individuals, who can also offer help, are present. At the heart of the bystander effects lies a strategic interdependence between the actions of the individuals who can potentially offer help,

\footnotetext{
${ }^{25}$ These tests are based on 62 observations in Bystander and 60 observations in Control. We use a Bonferroni correction to account for the fact that we are performing multiple tests of the same hypothesis. In fact, we cannot reject the null hypothesis of no differences in the ratings even without the Bonferroni correction (for all tests, the uncorrected $\mathrm{p}>0.39$ ).
} 
whereby it is sufficient that one person volunteers to help in order for the victim to receive help. This introduces two possible mechanisms that may lead to reduced willingness to help. On the one hand, individuals may be tempted to free-ride on others' help and so abstain from helping when there are others who can help instead. On the other hand, the responsibility to help may be "diffused" between several bystanders so that everyone feels less responsible if the recipient receives no help. Both mechanisms point towards an erosion of prosocial values and norms as the cause for the bystander effect observed in previous studies.

In line with the previous literature, in our modified dictator game we observe a drop in the individual willingness to give to a recipient when there is strategic interdependence among dictators' actions relative to a control treatment where such interdependence is absent. However, we also show that this drop in the willingness to give does not lead to a reduction of the recipient's welfare. First, the probability that at least one dictator gives to the recipient is higher in the presence of bystanders than in the control treatment. Second, because the average amount given conditional on giving is not different between treatments, the recipient's expected earnings are actually higher when bystanders are present.

These findings call into question the relatively pessimistic interpretation of the bystander effect as being driven by an erosion of prosocial values and social norms: based on these measures of the recipient's welfare, subjects in the bystander treatment do not seem to behave any less prosocially than those in the control treatment. Our analysis of dictators' beliefs and of norms of giving supports this as we do not find evidence to corroborate either free-riding on others' provision of help or a diffusion of responsibility explanation for the reduction in giving observed in the experiment. ${ }^{26}$

Overall, our experiment shows that the presence of bystanders may, in some situations, benefit the person in need. This may be of particular relevance in situations where the required help could be provided by one person only and where individuals may differ in the quality of help that they are willing or able to provide. Examples of such

\footnotetext{
${ }^{26}$ An important qualification of our conclusions, however, is that our experiment is designed to isolate the bystander effect stemming from the existence of a strategic interdependence between the bystanders' actions. Our experiment is not well-suited to study any effect that may arise due to the mere presence of other decisionmakers.
} 
situations include hospital appeals for organ donations and blood transfusions as well as requests made within organizations for one member to perform a certain task outside normal duties. In our study, we hold constant the number of individuals present and let dictators make their choices simultaneously to control for other potential effects from the presence of bystanders that may occur from the mere presence of a higher number of individuals. A potential area for future research could be to investigate how prosocial behaviour and the expected outcome for the recipient are sensitive to variations in the sheer number of bystanders. ${ }^{27}$

${ }^{27}$ For a first step in this direction, see Campos-Mercade (2017) 


\section{REFERENCES}

Barr, Abigail, Tom Lane, and Daniele Nosenzo. 2018. “On the Social Inappropriateness of Discrimination.” Journal of Public Economics 164 (153-164).

Barr, Abigail, and Georgia Michailidou. 2017. "Complicity without Connection or Communication.” Journal of Economic Behavior \& Organization 142: 1-10.

Bartling, Björn, Roberto A. Weber, and Lan Yao. 2015. "Do Markets Erode Social Responsibility?" The Quarterly Journal of Economics 130 (1): 219-66.

Behnk, Sascha, Li Hao, and Ernesto Reuben. 2017. "Partners in Crime: Diffusion of Responsibility in Antisocial Behaviors.” IZA Discussion Paper No. 11031.

Bicchieri, Cristina. 2006. The Grammar of Society: The Nature and Dynamics of Social Norms. Cambridge: Cambridge University Press.

Bohnet, Iris, and Bruno S. Frey. 1999. "Social Distance and Other-Regarding Behavior in Dictator Games: Comment." American Economic Review 89 (1): 335-39.

Campos-Mercade, Pol. 2017. "Helping Behavior and Group Size." Work in Progress.

Cettolin, Elena, Arno Riedl, and Giang Tran. 2017. "Giving in the Face of Risk." Journal of Risk and Uncertainty 55 (2): 95-118. https://doi.org/10.1007/s11166-017-92702.

Charness, Gary, and Uri Gneezy. 2008. "What's in a Name? Anonymity and Social Distance in Dictator and Ultimatum Games." Journal of Economic Behavior \& Organization 68 (1): 29-35.

Cryder, Cynthia E, and George Loewenstein. 2012. "Responsibility: The Tie That Binds." Journal of Experimental Social Psychology 48 (1): 441-45.

D’Adda, Giovanna, Michalis Drouvelis, and Daniele Nosenzo. 2016. "Norm Elicitation in Within-Subject Designs: Testing for Order Effects." Journal of Behavioral and Experimental Economics 62: 1-7. https://doi.org/10.1016/j.socec.2016.02.003.

Dana, Jason, George Loewenstein, RA Weber, D De Cremer, and AE Tenbrunsel. 2012. "Ethical Immunity: How People Violate Their Own Moral Standards without Feeling They Are Doing So.” Behavioral Business Ethics: Shaping an Emerging Field, 201-19.

Dana, Jason, Roberto Weber, and Jason Kuang. 2007. "Exploiting Moral Wiggle Room: Experiments Demonstrating an Illusory Preference for Fairness." Economic Theory 33 (1): 67-80.

Darley, John M, and Bibb Latané. 1968. "Bystander Intervention in Emergencies: Diffusion of Responsibility." Journal of Personality and Social Psychology 8 (4p1): 377.

Dufwenberg, Martin, and Astri Muren. 2006. "Generosity, Anonymity, Gender." Journal of Economic Behavior \& Organization 61 (1): 42-49.

Engelmann, Dirk, and Martin Strobel. 2000. "The False Consensus Effect Disappears If Representative Information and Monetary Incentives Are Given.” Experimental Economics 3 (3): 241-60.

- 2012. "Deconstruction and Reconstruction of an Anomaly." Games and Economic Behavior 76 (2): 678-89. 
Erkut, Hande, Daniele Nosenzo, and Martin Sefton. 2015. "Identifying Social Norms Using Coordination Games: Spectators vs. Stakeholders.” Economics Letters 130: $28-31$.

Falk, Armin, and Nora Szech. 2013. "Morals and Markets.” Science 340 (6133): 707-11. https://doi.org/10.1126/science.1231566.

Fischbacher, Urs. 2007. "Z-Tree: Zurich Toolbox for Ready-Made Economic Experiments." Experimental Economics 10 (2): 171-78.

Fischer, Peter, Joachim I Krueger, Tobias Greitemeyer, Claudia Vogrincic, Andreas Kastenmüller, Dieter Frey, Moritz Heene, Magdalena Wicher, and Martina Kainbacher. 2011. "The Bystander-Effect: A Meta-Analytic Review on Bystander Intervention in Dangerous and Non-Dangerous Emergencies." Psychological Bulletin 137 (4): 517.

Franzen, Axel. 1995. "Group Size and One-Shot Collective Action.” Rationality and Society 7 (2): 183-200.

Goeree, Jacob K., and Charles A. Holt. 2005. "An Experimental Study of Costly Coordination." Games and Economic Behavior 51 (2): 349-64.

Goeree, Jacob K, Charles A Holt, and Angela M Smith. 2017. "An Experimental Examination of the Volunteer's Dilemma." Games and Economic Behavior.

Greiner, Ben. 2015. "Subject Pool Recruitment Procedures: Organizing Experiments with ORSEE." Journal of the Economic Science Association 1 (1): 114-25.

Krupka, Erin, Stephen Leider, and Ming Jiang. 2016. "A Meeting of the Minds: Informal Agreements and Social Norms.” Management Science 63 (6): 1708-29.

Krupka, Erin, and Roberto A. Weber. 2013. "Identifying Social Norms Using Coordination Games: Why Does Dictator Game Sharing Vary?" Journal of the European Economic Association 11 (3): 495-524.

Latané, Bibb, and James M Dabbs Jr. 1975. "Sex, Group Size and Helping in Three Cities." Sociometry, 180-94.

Latané, Bibb, and John M. Darley. 1970. The Unresponsive Bystander: Why Doesn't He Help? Appleton-Century-Crofts.

Latané, Bibb, and Steve Nida. 1981. "Ten Years of Research on Group Size and Helping." Psychological Bulletin 89 (2): 308.

Moir, Rob. 1998. "A Monte Carlo Analysis of the Fisher Randomization Technique:

Reviving Randomization for Experimental Economists.” Experimental Economics 1 (1): 87-100.

Panchanathan, Karthik, Willem E. Frankenhuis, and Joan B. Silk. 2013. "The Bystander Effect in an N-Person Dictator Game." Organizational Behavior and Human Decision Processes 120 (2): 285-97. https://doi.org/10.1016/j.obhdp.2012.06.008.

Ross, Lee, David Greene, and Pamela House. 1977. "The 'False Consensus Effect': An Egocentric Bias in Social Perception and Attribution Processes." Journal of Experimental Social Psychology 13 (3): 279-301.

Selten, Reinhard. 1967. "Die Strategiemethode Zur Erforschung Des Eingeschränkt Rationalen Verhaltens Im Rahmen Eines Oligopolexperimentes." In Beiträge Zur 
Experimentellen Wirtschaftsforschung, 136-68. Tübingen: J.C.B. Mohr (Paul Siebeck).

Weesie, Jeroen, and Axel Franzen. 1998. "Cost Sharing in a Volunteer's Dilemma." Journal of Conflict Resolution 42 (5): 600-618.

Weisel, Ori, and Shaul Shalvi. 2015. "The Collaborative Roots of Corruption." Proceedings of the National Academy of Sciences 112 (34): 10651-56. 


\section{Appendix A: Manipulation of the Degree of Anonymity}

Our experimental design also varied the degree of anonymity between subjects matched within a group (anonymity was always preserved across groups). We did this to explore whether a reduction in anonymity may diminish or accentuate the effect of bystanders on giving. In situations where the social norm is known to prescribe giving, reducing anonymity has been shown to have a positive effect on the average amount given (e.g., Bohnet and Frey, 1999; Charness and Gneezy, 2008). In the presence of bystanders, it is not clear what the social norm is. Suppose that the social norm prescribes a positive level of giving, even in the presence of bystanders. Then individuals may be more inclined to follow the norm if their identity was revealed to others, thus moderating the (potential) negative consequences of the bystander effect. However, if the social norm, as suggested by Darley and Latané (1968), prescribes inaction in the presence of bystanders, reduced anonymity may very well decrease giving in the Bystander treatment. Varying anonymity across Bystander and Control treatments allows for testing whether the bystander effect is more or less prominent in a context with reduced anonymity.

To vary anonymity, we implemented our treatments in two different conditions. ${ }^{1}$ The only difference between the two conditions was that in one (the "partially anonymous" condition) we collected at the beginning of the experiment information about the first letters of a subject's forename and surname, and we then used these initials to "identify" subjects in the table summarizing the outcomes of the game that subjects were displayed at the end of the experiment. ${ }^{2}$ In the "fully anonymous" implementation of our treatments, we did not collect subjects' initials and the table summarising the outcomes of the experiment listed subjects using anonymous labels ("Participant A" or "Participant B" - see the instructions reproduced in Appendix B).

\footnotetext{
${ }^{1} \mathrm{We}$ had an equal number of subjects (72) in each treatment/condition.

${ }^{2}$ At the beginning of a session, the experimenter explained how subjects' initials would be used in the course of the experiment. Subjects thereafter entered their initials into the computer. The experimenter verified that each subject had entered their initials truthfully by comparing this information with their student ID.
} 
Table A.1 summarizes the outcomes of the experiment by treatment and anonymity condition. We find no difference in any of the experimental outcomes across the partial and fully anonymous implementations of the experiment. ${ }^{3}$

Table A.1 - Outcomes of the experiment by treatment and anonymity condition

\begin{tabular}{|c|c|c|c|c|}
\hline & \multicolumn{2}{|c|}{ Fully anonymous } & \multicolumn{2}{|c|}{ Partially anonymous } \\
\hline & Bystander & Control & Bystander & Control \\
\hline $\begin{array}{l}\text { Giving rate ( } \% \text { of dictators who } \\
\text { chose to give) }\end{array}$ & $35 \%$ & $44 \%$ & $32 \%$ & $44 \%$ \\
\hline Average amount given & $0.97(1.58)$ & $1.35(1.84)$ & $0.84(1.46)$ & $1.52(2.18)$ \\
\hline $\begin{array}{l}\text { Average amount given, } \\
\text { conditional on giving }\end{array}$ & $2.77(1.44)$ & $3.04(1.57)$ & $2.65(1.39)$ & $3.43(2.04)$ \\
\hline $\begin{array}{l}\text { Probability that recipient receives } \\
\text { positive earnings }\end{array}$ & $95 \%$ & $44 \%$ & $93 \%$ & $44 \%$ \\
\hline Recipient's expected earnings & 2.63 & 1.35 & 2.46 & 1.52 \\
\hline
\end{tabular}

Note: Standard deviations in parentheses. In Bystander the probability that the recipient receives positive earnings is computed as $1-\left(1-p_{B}\right)^{n}$, where $p_{B}$ is the giving rate and $n=7$. In Control it is equal to the giving rate. In Bystander the recipient's expected earnings are computed as $\left[1-\left(1-p_{B}\right)^{n}\right] \bar{t}_{B}{ }^{+}$where $\bar{t}_{B}{ }^{+}$ is the average amount given, conditional on giving. In Control the recipient's expected earnings are equal to the average amount given.

Given the absence of significant differences across anonymity conditions, in the paper we have pooled the data across these conditions and presented the aggregated results. In the following, we reproduce the analysis reported in the paper separately for the fully and partially anonymous implementations of the experiment. As shown in Table A.1 our main

${ }^{3}$ Giving rate: $\chi^{2}$ tests, Bystander $\chi^{2}(1)=0.14, p=0.70$; Control $\chi^{2}(1)=0.00, p=1.00$. Amount given: Fisher's randomization tests, Bystander $p=0.68$; Control $p=0.66$. Amount given conditional on giving: Fisher's randomization tests, Bystander $\mathrm{p}=0.83$; Control $\mathrm{p}=0.47$. Probability that recipient receives positive earnings (using realized probabilities): Fisher's randomization tests, Bystander $p=1.00$; Control $p=1.00$. Recipient's expected earnings (using realized earnings): Fisher's randomization tests, Bystander $\mathrm{p}=0.49$; Control $\mathrm{p}=0.68$. 
results hold qualitatively for both implementations although, in some cases, our tests do not reach statistical significance at conventional levels, possibly due to the reduced sample size.

In particular, we find that the giving rate is lower in Bystander compared to Control both under the fully and partially anonymous implementations of the experiment. However, these differences are statistically insignificant $\left(\chi^{2}(1)=1.19, p=0.28\right.$ and $\chi^{2}(1)=2.15, p=$ 0.14, respectively). The average amount given is also lower in Bystander than in Control under both anonymity conditions, although the difference is significant only in the partially anonymous condition (Fisher's randomization tests, $p=0.23$ fully anonymous and $p=0.04$ partially anonymous). This could reflect the fact that, as discussed above, reduced anonymity may affect willingness to comply with norms in the Control or Bystander treatments, relative to the condition with full anonymity.

As in the pooled data, the probability that the recipient receives positive earnings is substantially higher in the Bystander treatment compared to Control, under both anonymity conditions. When we calculate this for each group separately, based on the choices by the seven dictators in that group, we find significant differences between Bystander and Control under both fully and partially anonymous conditions (Fisher's randomization tests, $p<0.01$ in both conditions). Also similarly to the pooled data, we find no significant differences in the amount given, conditional on giving, across the Bystander and Control treatments in either anonymity condition (Fisher's randomization test, $\mathrm{p}=0.58$ fully anonymous and $\mathrm{p}=$ 0.15 partially anonymous). As a consequence, the recipient's expected earnings are higher in Bystander compared to Control under both anonymity conditions. Computing realized expected earnings using the choices of the seven dictators in each group, we find that the difference is significant in the fully anonymous condition (Fisher's randomization test, $\mathrm{p}=$ 0.03 ), but not in the partially anonymous condition (Fisher's randomization test, $\mathrm{p}=0.21$ ).

Turning to differences in beliefs in the Bystander treatment, under both anonymity conditions we find that, compared to dictators who give a positive amount, dictators who do not give believe that significantly fewer others in their group give and that the average amount given is significantly smaller (Fisher's randomization tests, in all comparisons $\mathrm{p}<$ 0.01). Similarly, running separate Tobit regressions for fully and partially anonymous conditions of a dictator's own giving on their belief of the average amount given by others 
in their group shows that a strong positive correlation between the two measures emerges in both cases (fully anonymous: coefficient $2.26, \mathrm{t}=3.81, \mathrm{p}<0.01$; partially anonymous: coefficient 2.11, $\mathrm{t}=3.31, \mathrm{p}<0.01)$.

Finally, our norm elicitation experiment was also implemented under both fully and partially anonymous conditions. ${ }^{4}$ In the partially anonymous implementation, subjects were asked to rate the appropriateness of the dictator's actions knowing that dictators would be identified by their name initials in the course of the experiment.

Figure A.1 shows the average appropriateness ratings of the 11 dictator actions across Bystander and Control treatments and fully and partially anonymous conditions. There are only small differences in ratings across fully and partially anonymous conditions, and in all cases no difference is significant at the $10 \%$ level using Fisher's randomization tests. Moreover, we do not detect any significant differences in the ratings of Bystander and Control under either anonymity condition (all Fisher's randomization tests insignificant at the $10 \%$ level). ${ }^{5}$

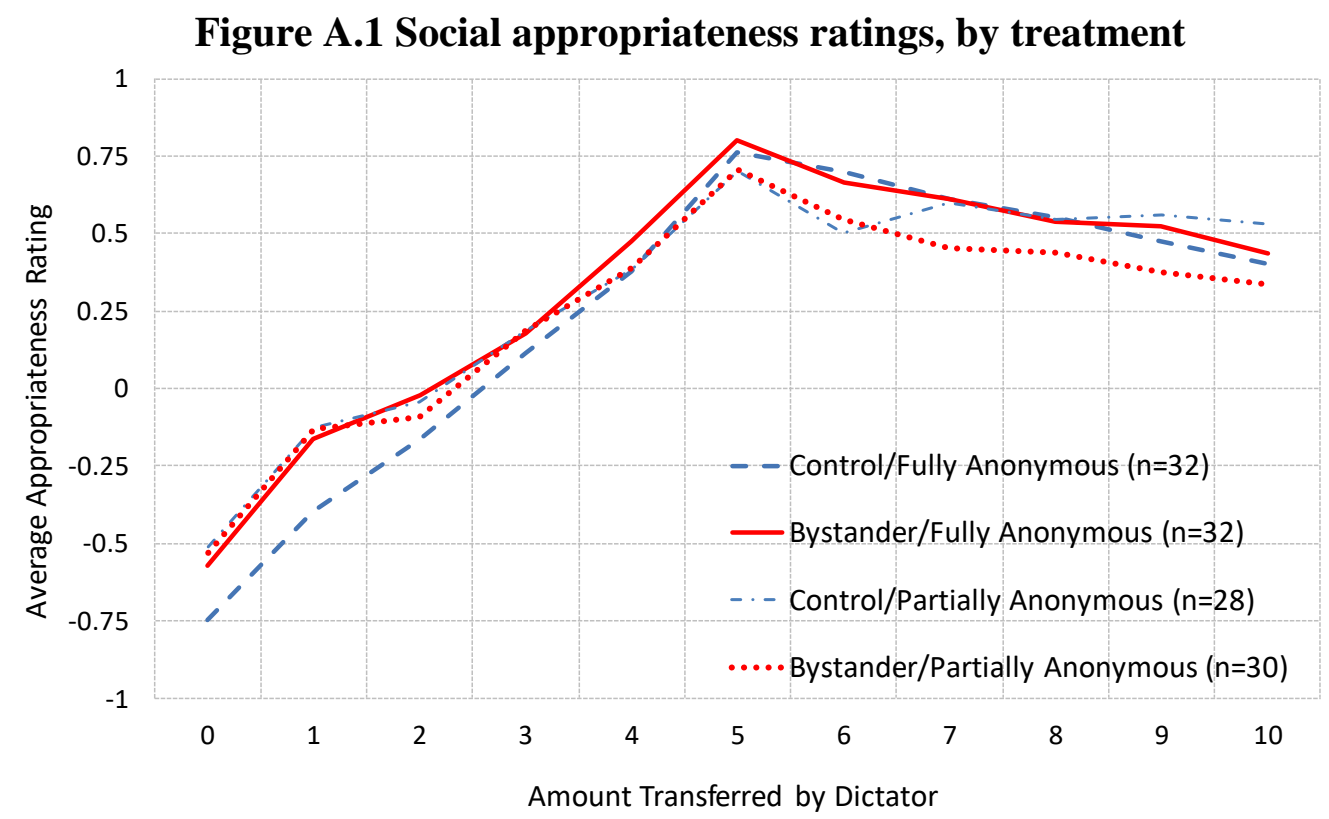

\footnotetext{
${ }^{4}$ In the fully anonymous implementation we had 32 subjects in Control and 32 subjects in Bystander. In the partially anonymous implementation we had 28 subjects in Control and 30 subjects in Bystander.

${ }^{5}$ Note that, in order to correct for multiple comparisons, we apply a Bonferroni correction when reporting these tests.
} 


\section{Appendix B: Instructions}

In the main experiment, subjects received instructions about the dictator game at the beginning of a session. Instructions were distributed in hard-copy and read aloud by the experimenter. Before starting, all subjects answered a set of control questions. Subjects were informed about the belief elicitation task only after they had made their choices in the dictator game. The instructions for the belief elicitation task were presented on subjects' computer screens which they read in private.

In the norm elicitation experiment, subjects were distributed two sets of hard-copy instructions. The instructions were read aloud by the experimenter and included control questions. The first set of instructions explained the norm elicitation procedure and how subjects' earnings would be determined and was identical across treatments. The second set of instructions described the dictator game that subjects were asked to evaluate and differed across Bystander and Control treatments.

\section{B.1 Main Experiment}

Instructions in the Control and the Bystander treatments of the dictator game experiments are reproduced below. These instructions refer to the fully anonymous implementation of the two treatments (i.e. without having subjects identified by their name initials).

\section{B.1.1 Control treatment}

\section{Instructions}

Welcome to this experiment. This is an experiment about decision-making. You will have a chance to earn money, depending on your choices and the choices of others. Earnings will be paid out to you in private and in cash at the end of the experiment.

There are other people in this room, who are also participating in this experiment. Everyone is participating for the first time, and all participants are reading the same instructions. During the experiment, we request that you turn off your mobile phone, remain quiet and do not attempt to communicate with other participants. Participants not following this request may be asked to leave without receiving payment. If you have any questions, please raise your hand and the experimenter will come to you.

In this experiment you will be randomly assigned to a group with seven other people in this room, forming a group of eight. During the experiment, any decisions that you make may affect the earnings of other members of your group. Similarly, the decisions of the other members of your group may affect your earnings. 
At the beginning of the experiment, each group member will be allocated $£ 10$. The computer will then randomly assign roles to the group members. One group member will be randomly assigned the role of ' $A$ ', while the other seven group members will be assigned the role of ' $\mathrm{B}$ '. The participant assigned role A will not make any decision in today's experiment. Participants assigned role $\mathrm{B}$ will be asked to make decisions. The computer will inform you of your role at the beginning of the experiment. Your role will stay the same throughout the experiment.

Once roles have been randomly assigned, the initial earnings of participant A will be reduced to $£ 0$. The initial earnings of the seven participants $B$ will not be reduced, so that they will start with $£ 10$ each.

Each participant B will then decide whether to transfer money from his or her $£ 10$ to participant A. Participants B will choose between two options:

- PASS - then no money will be transferred to A, and B will keep his or her own $£ 10$.

- TRANSFER - then B has to decide an amount T, between $£ 1$ and $£ 10$, to transfer from his or her own $£ 10$ to A.

Participants B will make their decision on a computer screen similar to that shown below:

You have the role of $B$.

You have to decide whether to PASS or TRANSFER and, if so, how much you wish to transfer to participant A.

Once you have made your decision, click the SUBMIT button.

O PASS $\quad$ TRANSFER

Please indicate the amount you wish to transfer:

Transfer $£ 1$

- Transfer £2

Transfer $£ 3$

Transfer $£ 4$

- Transfer £5

- Transfer £6

- Transfer £7

- Transfer £8

- Transfer $£ 9$

Transfer £10

Although we ask all seven participants B in the group to make a decision, only one participant $\mathrm{B}$ will be matched with participant $\mathrm{A}$ and thereby have his or her decision implemented. At the end of the experiment the computer will determine which of the seven participants B is matched with A at random. Therefore, one of two possible situations will arise: 
- The randomly selected participant $B$ has chosen to PASS. Then the seven participants B will earn $£ 10$ each and participant A will earn $£ 0$.

- The randomly selected participant $B$ has chosen to TRANSFER. Then his or her monetary transfer will be implemented. The selected participant B will earn $£ 10$ $£ T$ (the amount transferred). Participant A will earn $£$ T. The other six participants $\mathrm{B}$ will earn $£ 10$ each.

So, to recap, if you are a participant A you will not have a decision to make in today's experiment. If you are participant B:

- You will be asked to choose whether to PASS or TRANSFER.

- If you are randomly selected by the computer and you choose to TRANSFER, participant A will receive your monetary transfer.

- If you are randomly selected by the computer and you choose to PASS, participant A will receive $£ 0$.

- If you are not randomly selected by the computer, your decision will not be implemented. The decision of the randomly selected participant $\mathrm{B}$ will be implemented instead.

At the end of the experiment the computer will inform all group members of the decisions made by the seven participants B in the group. The computer will also inform all group members of which participant B has been selected, and the corresponding earnings of each group member.

This information will be shown to you using a computer screen similar to that shown below.

Outcome in your group:

\begin{tabular}{|c||c||c||c|}
\hline Participant & Decision & Selected & Earnings \\
\hline \hline A & - & - & $x x x$ \\
B & $x x x$ & $x x x$ & $x x x$ \\
B & $x x x$ & $x x x$ & $x x x$ \\
B & $x x x$ & $x x x$ & $x x x$ \\
B & $x x x$ & $x x x$ & $x x x$ \\
B & $x x x$ & $x x x$ & $x x x$ \\
B & $x x x$ & $x x x$ & $x x x$ \\
B & $x x x$ & $x x x$ & $x x x$ \\
\hline
\end{tabular}

The first column shows the role of each participant and the second column shows the decision made by each participant. The third column shows whether the participant has been selected by the computer and the fourth column shows each participant's earnings.

Thereafter, the experiment will end and all participants will be paid their earnings in private and in cash. 
Please raise your hand if you have any questions.

Before we continue with the experiment we want to check that each participant understands how their earnings will be calculated. To do this we ask you to answer the questions below. In a couple of minutes the experimenter will check your answers. When each participant has answered all questions correctly we will continue with the experiment.

If you have a question at any time, raise your hand and the experimenter will come to your desk to answer it.

\section{Questions}

1) How many participants will be asked to make a decision?
a) One participant $B$
b) Two, participant A and one participant B
c) All seven participants B

2) How many participants will at most be matched with participant A?
a) Seven
b) One
c) Zero

3) One of the following statements is false. Please indicate which one is false by putting an ' $\mathrm{X}$ ' next to it.

a) If six participants $B$ decide to PASS and one participant $B$ decides to TRANSFER $£ 4$, and this participant $B$ is randomly selected to be matched with $A$, then A will earn $£ 4$, the selected participant B will earn $£ 6$ and the other six participants B will earn $£ 10$ each.

b) If all participants B decide to PASS, then A will earn $£ 0$ and the seven participants B will earn $£ 10$ each.

c) If two participants B decide to TRANSFER and the other five decide to PASS, and one of the participants B who decided to PASS is randomly selected to be matched with A, then A will earn $£ 6$, the selected participant B will earn $£ 4$, and the six other participants B will earn $£ 10$ each.

4) Suppose that in one group the participants B make their decisions as follows:

Participant B1: TRANSFER £7

Participant B2: PASS

Participant B3: TRANSFER £2

Participant B4: TRANSFER £1

Participant B5: PASS

Participant B6: TRANSFER £10

Participant B7: PASS

The computer randomly selects participant B3 to be matched with participant A. Please indicate the earnings of all participants in this group: 
Participant A:

Participant B3:

Participant B6:
Participant B1:

Participant B4:

Participant B7:
Participant B2:

Participant B5:

\section{B.1.2 Bystander treatment}

\section{Instructions}

Welcome to this experiment. This is an experiment about decision-making. You will have a chance to earn money, depending on your choices and the choices of others. Earnings will be paid out to you in private and in cash at the end of the experiment.

There are other people in this room, who are also participating in this experiment. Everyone is participating for the first time, and all participants are reading the same instructions. During the experiment, we request that you turn off your mobile phone, remain quiet and do not attempt to communicate with other participants. Participants not following this request may be asked to leave without receiving payment. If you have any questions, please raise your hand and the experimenter will come to you.

In this experiment you will be randomly assigned to a group with seven other people in this room, forming a group of eight. During the experiment, any decisions that you make may affect the earnings of other members of your group. Similarly, the decisions of the other members of your group may affect your earnings.

At the beginning of the experiment, each group member will be allocated $£ 10$. The computer will then randomly assign roles to the group members. One group member will be randomly assigned the role of ' $A$ ', while the other seven group members will be assigned the role of ' $\mathbf{B}$ '. The participant assigned role A will not make any decision in today's experiment. Participants assigned role B will be asked to make decisions. The computer will inform you of your role at the beginning of the experiment. Your role will stay the same throughout the experiment.

Once roles have been randomly assigned, the initial earnings of participant A will be reduced to $£ 0$. The initial earnings of the seven participants $B$ will not be reduced, so that they will start with $£ 10$ each.

Each participant B will then decide whether to transfer money from his or her $£ 10$ to participant A. Participants B will choose between two options:

- PASS - then no money will be transferred to A, and B will keep his or her own $£ 10$.

- TRANSFER - then B has to decide an amount T, between $£ 1$ and $£ 10$, to transfer from his or her own $£ 10$ to A.

Participants B will make their decision on a computer screen similar to that shown below: 
Please indicate the amount you wish to transfer:
- Transfer £1
Transfer £2
Transfer £3
- Transfer £4
- Transfer £5
- Transfer £6
- Transfer $£ 7$
- Transfer £8
- Transfer £9
- Transfer £10

Although we ask all seven participants B in the group to make a decision, at most one participant $\mathrm{B}$ will be matched with participant $\mathrm{A}$ and thereby have his or her decision implemented. At the end of the experiment the computer will determine which (if any) of the seven participants $\mathrm{B}$ is matched with A using the following criterion:

- If a participant B has chosen to PASS, then he or she will not be selected by the computer.

- If a participant B has chosen to TRANSFER, then he or she may be selected by the computer.

Therefore, based on the decisions of the seven participants $\mathrm{B}$, one of three possible situations will arise:

- No participant B has chosen to TRANSFER (i.e., all participants B have chosen to PASS). Then no participant B will be matched with A. The seven participants B will earn $£ 10$ each and participant A will earn $£ 0$.

- Only one participant B has chosen to TRANSFER. Then this participant B will be matched with A. His or her monetary transfer will be implemented. The selected participant B will earn $£ 10$ - £T (the amount transferred). Participant A will earn $£$ T. The other six participants B will earn $£ 10$ each.

- More than one participants B have chosen to TRANSFER. Then one of these participants B will be selected by the computer at random. His or her monetary transfer will be implemented. The selected participant B will earn $£ 10-£ T$. Participant A will earn $£$ T. The other six participants B will earn $£ 10$ each. 
So, to recap, if you are a participant A you will not have a decision to make in today's experiment.

If you are participant $B$ :

- You will be asked to choose whether to PASS or TRANSFER.

- If you choose to TRANSFER and you are the only participant B who has chosen to TRANSFER, you will be matched with participant A and participant A will receive your monetary transfer.

- If you choose to TRANSFER and you are not the only participant B who has chosen to TRANSFER, you will be matched with participant A and participant A will receive your monetary transfer as long as you are randomly selected by the computer.

- If you choose to PASS, you will not be matched with participant A. Participant A will receive a monetary transfer from one of the other six participants B as long as one of them has chosen to TRANSFER.

At the end of the experiment the computer will inform all group members of the decisions made by the seven participants B in the group. The computer will also inform all group members of which (if any) participant B has been selected, and the corresponding earnings of each group member.

This information will be shown to you using a computer screen similar to that shown below.

Outcome in your group:

\begin{tabular}{|c||c||c||c|}
\hline Participant & Decision & Selected & Earnings \\
\hline A & - & - & $x x x$ \\
B & $x x x$ & $x x x$ & $x x x$ \\
B & $x x x$ & $x x x$ & $x x x$ \\
B & $x x x$ & $x x x$ & $x x x$ \\
B & $x x x$ & $x x x$ & $x x x$ \\
B & $x x x$ & $x x x$ & $x x x$ \\
B & $x x x$ & $x x x$ & $x x x$ \\
B & $x x x$ & $x x x$ & $x x x$ \\
\hline
\end{tabular}

The first column shows the role of each participant and the second column shows the decision made by each participant. The third column shows whether the participant has been selected by the computer and the fourth column shows each participant's earnings.

Thereafter, the experiment will end and all participants will be paid their earnings in private and in cash.

Please raise your hand if you have any questions. 
Before we continue with the experiment we want to check that each participant understands how their earnings will be calculated. To do this we ask you to answer the questions below. In a couple of minutes the experimenter will check your answers. When each participant has answered all questions correctly we will continue with the experiment.

If you have a question at any time, raise your hand and the experimenter will come to your desk to answer it.

\section{Questions}

1) How many participants will be asked to make a decision?

a) One participant B b) Two, participant $A$ and one participant $B$

c) All seven participants B

2) How many participants will at most be matched with participant A?
a) Seven
b) One
c) Zero

3) One of the following statements is false. Please indicate which one is false by putting an ' $\mathrm{X}$ ' next to it.

a) If six participants B decide to PASS and one participant B decides to TRANSFER $£ 4$, then this participant B will be matched with A. A will earn $£ 4$, the selected participant B will earn $£ 6$ and the other six participants B will earn $£ 10$ each.

b) If all participants B decide to PASS, then no participant B will be matched with A. A will earn $£ 0$ and the seven participants $B$ will earn $£ 10$ each.

c) If two participants B decide to TRANSFER and the other five decide to PASS, then one of the participants B who decided to PASS will be matched with A. A will earn $£ 6$, the selected participant B will earn $£ 4$, and the six other participants B will earn $£ 10$ each.

4) Suppose that in one group the participants B make their decisions as follows:

Participant B1: TRANSFER $£ 7$

Participant B2: PASS

Participant B3: TRANSFER £2

Participant B4: TRANSFER $£ 1$

Participant B5: PASS

Participant B6: TRANSFER $£ 10$

Participant B7: PASS

The computer randomly selects participant B3 to be matched with participant A. Please indicate the earnings of all participants in this group:

Participant A:

Participant B1:

Participant B2:

Participant B3:

Participant B4:

Participant B5: 
Participant B6:

Participant B7:

\section{B.2 Norm Elicitation Experiments}

Instructions in the Bystander and Control treatments of the norm elicitation experiments are included below.

\section{B.2.1 Introductory Instructions, common to both treatments}

\section{Instructions}

Welcome to this experiment. This is an experiment about decision-making. During the experiment, we request that you remain quiet and do not attempt to communicate with other participants. Participants not following this request may be asked to leave without receiving payment. If you have any questions, please raise your hand and the experimenter will come to you. For your participation, you will be paid a show-up fee of $£ 4$. You may also receive some additional money based on your choices and the choices of others in the task described below.

In a few minutes you will read a description of a situation. This description corresponds to a situation in which one person must decide how to act. You will be given a description of various possible actions the person can choose to take.

After you have read the description of the situation, you will be asked to evaluate the different possible actions the person can choose to take. You must indicate, for each of the possible actions, whether taking that action would be "socially appropriate" or "socially inappropriate". By socially appropriate, we mean behaviour that you think most participants would agree is the "correct" thing to do. Another way to think about what we mean is that if the person were to select a socially inappropriate action, then someone else might be angry with the person.

In each of your responses, we would like you to answer as truthfully as possible, based on your opinion of what constitutes socially appropriate or socially inappropriate behaviour.

To give you an idea of how the experiment will proceed, we will go through an example situation and show you how you will indicate your responses.

\section{Example Situation}

A person is at a local coffee shop near campus. While there, the person notices that someone has left a wallet at one of the tables. The person can choose between four possible actions: take the wallet, ask others nearby if the wallet belongs to them, leave the wallet where it is, or give the wallet to the shop manager.

The table below presents the list of the possible actions the person can choose. For each of the actions, you would be asked to indicate whether you believe choosing that action is very socially inappropriate, socially inappropriate, somewhat socially inappropriate, somewhat 
socially appropriate, socially appropriate, or very socially appropriate. To indicate your response, you would click on the corresponding button.

\begin{tabular}{|c|c|c|c|c|c|c|}
\hline The person chooses to: & $\begin{array}{l}\text { Very socially } \\
\text { inappropriate }\end{array}$ & $\begin{array}{c}\text { Socially } \\
\text { inappropriate }\end{array}$ & $\begin{array}{l}\text { Somewhat } \\
\text { socially } \\
\text { inappropriate }\end{array}$ & $\begin{array}{l}\text { Somewhat } \\
\text { socially } \\
\text { appropriate }\end{array}$ & $\begin{array}{l}\text { Socially } \\
\text { appropriate }\end{array}$ & $\begin{array}{l}\text { Very socially } \\
\text { appropriate }\end{array}$ \\
\hline Take the wallet & $c$ & $c$ & $c$ & $c$ & $c$ & $c$ \\
\hline $\begin{array}{l}\text { Ask others nearby if the wallet } \\
\text { belongs to them }\end{array}$ & $c$ & $c$ & $c$ & $c$ & $c$ & $c$ \\
\hline Leave the wallet where it is & $r$ & $r$ & $r$ & $r$ & $r$ & $r$ \\
\hline Give the wallet to the shop manager & c & $r$ & $r$ & c & $c$ & $r$ \\
\hline
\end{tabular}

If this were the situation for this study, you would consider each of the possible actions above and, for that action, indicate the extent to which you believe taking that action would be "socially appropriate" or "socially inappropriate". Recall that by socially appropriate we mean behaviour that most participants agree is the "correct" thing to do.

For example, suppose you thought that taking the wallet was very socially inappropriate, asking others nearby if the wallet belongs to them was somewhat socially appropriate, leaving the wallet where it is was somewhat socially inappropriate, and giving the wallet to the shop manager was very socially appropriate. Then you would indicate your responses as follows:

\begin{tabular}{|c|c|c|c|c|c|c|}
\hline The person chooses to: & $\begin{array}{l}\text { Very socially } \\
\text { inappropriate }\end{array}$ & $\begin{array}{c}\text { Socially } \\
\text { inappropriate }\end{array}$ & $\begin{array}{l}\text { Somewhat } \\
\text { socially } \\
\text { inappropriate }\end{array}$ & $\begin{array}{l}\text { Somewhat } \\
\text { socially } \\
\text { appropriate }\end{array}$ & $\begin{array}{c}\text { Socially } \\
\text { appropriate }\end{array}$ & $\begin{array}{l}\text { Very socially } \\
\text { appropriate }\end{array}$ \\
\hline Take the wallet & $\bullet$ & $r$ & $r$ & $r$ & $c$ & $c$ \\
\hline $\begin{array}{l}\text { Ask others nearby if the wallet } \\
\text { belongs to them }\end{array}$ & $c$ & $r$ & $c$ & 6 & $c$ & $c$ \\
\hline Leave the wallet where it is & $r$ & $c$ & $\bullet$ & $r$ & $c$ & $c$ \\
\hline Give the wallet to the shop manager & $c$ & $c$ & $c$ & $c$ & $c$ & - \\
\hline
\end{tabular}

If you have any questions about this example situation or about how to indicate your responses, please raise your hand now.

\section{Your Task in Today's Experiment}

You will next read the description of a situation where a person who is a participant in an experiment must choose between various possible actions. After you read the description, you must consider the possible actions and indicate on your computer screen how socially appropriate these are in a table similar to the one shown above for the example situation.

\section{How Your Cash Earnings Are Determined}

At the end of the experiment today the computer will randomly select one of the possible actions that the person could have taken. The computer will then randomly match you with one other participant in this room. Your evaluation of the selected action will be compared 
with that of the randomly selected participant. If your evaluation is the same as theirs, you will receive $£ 8$ for this task; otherwise you will receive zero.

For instance, imagine the example situation above was the actual situation and the possible action "Leave the wallet where it is" was selected by the computer. If your evaluation had been "somewhat socially inappropriate" then your task earnings would be $£ 8$ if the person you are matched with also evaluated the action as "somewhat socially inappropriate" and zero otherwise.

Before we continue with the experiment we want to check that each participant understands how their earnings will be calculated. To do this we ask you to answer the questions below. In a couple of minutes the experimenter will check your answers. When each participant has answered all questions correctly we will continue with the experiment.

If you have a question at any time, raise your hand and the experimenter will come to your desk to answer it.

\section{Questions}

1. For the action selected for payment, if your rating is "Very socially appropriate" and the rating of the participant who is randomly matched with you is "Very socially appropriate", your earnings are:

2. For the action selected for payment, if your rating is "Very socially appropriate" and the rating of the participant who is randomly matched with you is "Socially inappropriate", your earnings are:

\section{B.2.2 Situation Instructions, Control treatment}

\section{Situation}

The situation you are asked to evaluate deals with the behaviour of a participant in an experiment. At the beginning of the experiment, the participant is assigned to a group with seven other people, forming a group of eight.

Each group member is allocated $£ 10$. Thereafter, the computer randomly assigns roles to the group members. One group member is assigned the role of ' $\mathrm{A}$ ', while the other seven group members are assigned the role of ' $\mathrm{B}$ '.

Thereafter, the initial earnings of participant $A$ are reduced to $£ 0$. The initial earnings of the seven participants B are not reduced so that they start with $£ 10$ each. The participant assigned role A does not make any decisions in the experiment. Participants assigned role $\mathrm{B}$ are asked to make one decision each.

Each participant B decides whether to transfer money from his or her $£ 10$ to participant $\mathrm{A}$. Participants B choose between two options:

- $\quad$ PASS - then no money is transferred to A, and B keeps his or her own $£ 10$. 
- TRANSFER - then $B$ has to decide an amount $\mathrm{T}$, between $£ 1$ and $£ 10$, to transfer from his or her own $£ 10$ to A.

Participants B make their decision on a computer screen similar to that shown below:
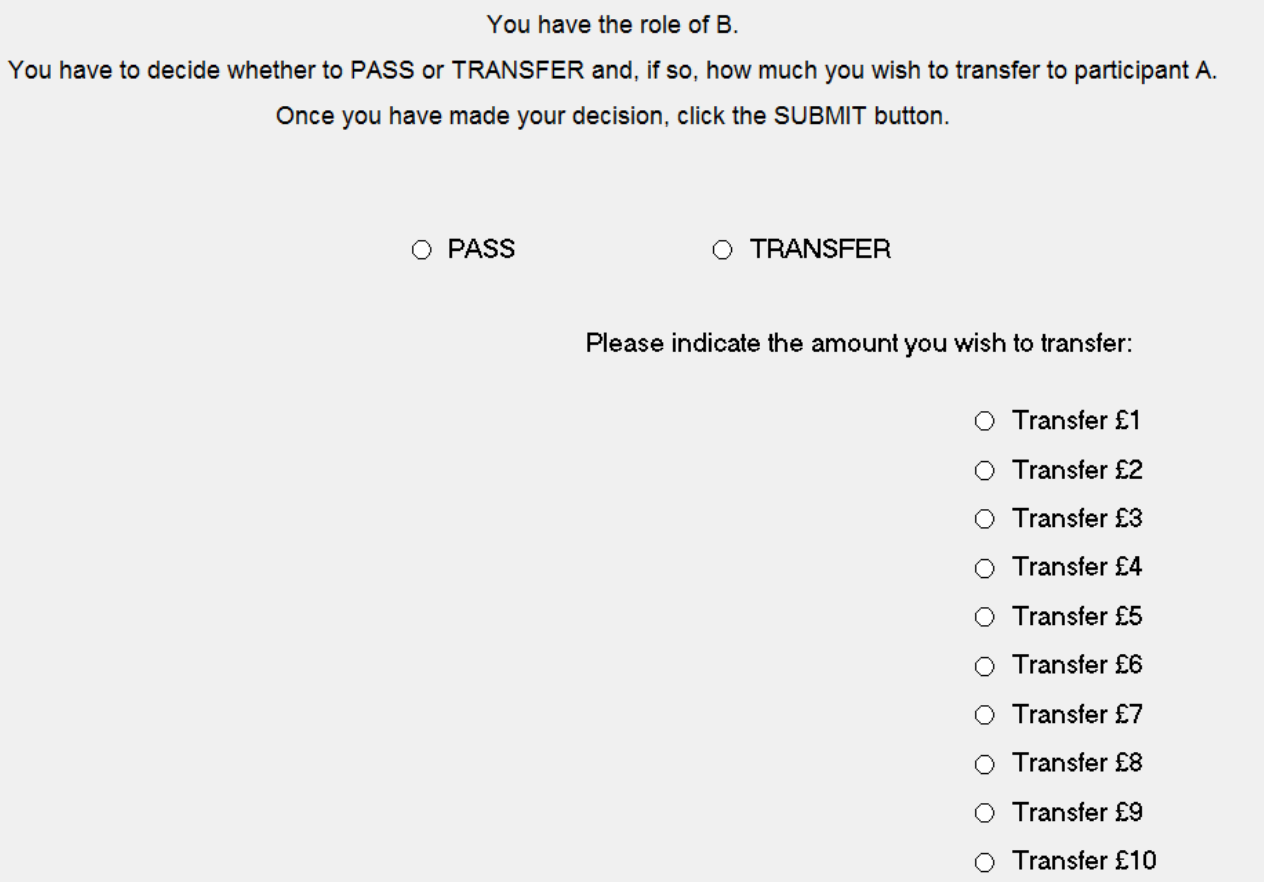

Although all seven participants B in the group make a decision, only one participant B is matched with participant A and thereby has his or her decision implemented. At the end of the experiment the computer determines which of the seven participants B is matched with A at random. Therefore, one of two possible situations arises:

- The randomly selected participant B has chosen to PASS. Then the seven participants B earn $£ 10$ each and participant A earns $£ 0$.

- The randomly selected participant B has chosen to TRANSFER. Then his or her monetary transfer is implemented. The selected participant B earns $£ 10-£ T$ (the amount transferred). Participant A earns $£$ T. The other six participants B earn $£ 10$ each.

So, to recap: participant A does not have a decision to make in the experiment.

For participants B:

- Participants B are asked to choose whether to PASS or TRANSFER.

- If a participant $B$ is randomly selected by the computer and he or she has chosen to TRANSFER, participant A receives his or her monetary transfer.

- If a participant B is randomly selected by the computer and he or she has chosen to PASS, participant A receives $£ 0$. 
- If a participant B is not randomly selected by the computer, his or her decision is not implemented. The decision of the randomly selected participant $\mathrm{B}$ is implemented instead.

At the end of the experiment the computer informs all group members of the decisions made by the seven participants B in the group. The computer also informs all group members of which participant B has been selected, and the corresponding earnings of each group member.

This information is shown to each participant using a computer screen similar to that shown below.

$$
\text { Outcome in your group: }
$$

\begin{tabular}{|c||c||c||c|}
\hline Participant & Decision & Selected & Earnings \\
\hline \hline A & - & - & $x x x$ \\
B & $x x x$ & $x x x$ & $x x x$ \\
B & $x x x$ & $x x x$ & $x x x$ \\
B & $x x x$ & $x x x$ & $x x x$ \\
B & $x x x$ & $x x x$ & $x x x$ \\
B & $x x x$ & $x x x$ & $x x x$ \\
B & $x x x$ & $x x x$ & $x x x$ \\
B & $x x x$ & $x x x$ & $x x x$ \\
\hline
\end{tabular}

The first column shows the role of each participant and the second column shows the decision made by each participant. The third column shows whether the participant has been selected by the computer and the fourth column shows each participant's earnings.

Thereafter, the experiment ends and all participants are paid their earnings in private and in cash.

\section{-- End of the description of the situation --}

Before we continue with this experiment we want to check that each participant understands how the earnings in the situation described above would be calculated. To do this we ask you to answer the questions below. In a couple of minutes the experimenter will check your answers. When each participant has answered all questions correctly we will continue with this experiment.

If you have a question at any time, raise your hand and the experimenter will come to your desk to answer it.

\section{Questions About The Situation}

1) How many participants are asked to make a decision?
a) One participant $B$
b) Two, participant A and one participant B
c) All seven participants B 
2) How many participants at most are matched with participant A?
a) Seven
b) One
c) Zero

3) One of the following statements is false. Please indicate which one is false by putting an ' $\mathrm{X}$ ' next to it.

a) If six participants $B$ decide to PASS and one participant $B$ decides to TRANSFER $£ 4$, and this participant $B$ is randomly selected to be matched with $A$, then A earns $£ 4$, the selected participant B earns £6 and the other six participants B earn £10 each.

b) If all participants B decide to PASS, then A earns $£ 0$ and the seven participants B earn $£ 10$ each.

c) If two participants B decide to TRANSFER and the other five decide to PASS, and one of the participants $B$ who decide to PASS is randomly selected to be matched with A, then A earns $£ 6$, the selected participant B earns $£ 4$, and the six other participants B earn $£ 10$ each.

4) Suppose that in one group the participants B make their decisions as follows:

Participant B1: TRANSFER £7

Participant B2: PASS

Participant B3: TRANSFER £2

Participant B4: TRANSFER £1

Participant B5: PASS

Participant B6: TRANSFER £10

Participant B7: PASS

The computer randomly selects participant B3 to be matched with participant A. Please indicate the earnings of all participants in this group:

Participant A:

Participant B1:

Participant B2:

Participant B3:

Participant B4:

Participant B5:

Participant B6:

Participant B7:

\section{Your task in today's experiment}

Your task in today's experiment is to evaluate the different possible actions available to one of the participants $B$ in the situation described above.

On your computer screen you will see a table where you must indicate, for each of the 11 possible actions available to the participant $\mathrm{B}$, whether you believe that choosing that action is very socially inappropriate, socially inappropriate, somewhat socially inappropriate, somewhat socially appropriate, socially appropriate, or very socially appropriate. Recall that by socially appropriate, we mean behaviour that you think most participants would 
agree is the "correct" thing to do. To indicate your response, please choose one option in each row.

At the end of the experiment, we will randomly select one of the possible actions that the participant $\mathrm{B}$ could have taken. If your evaluation matches the response of the other participant who is matched with you, you will receive $£ 8$, otherwise you will receive zero.

Please now look at your computer screen and indicate your responses.

\section{B.2.3 Situation Instructions, Bystander treatment}

\section{Situation}

The situation you are asked to evaluate deals with the behaviour of a participant in an experiment. At the beginning of the experiment, the participant is assigned to a group with seven other people, forming a group of eight.

Each group member is allocated $£ 10$. Thereafter, the computer randomly assigns roles to the group members. One group member is assigned the role of ' $\mathrm{A}$ ', while the other seven group members are assigned the role of ' $\mathrm{B}$ '.

Thereafter, the initial earnings of participant $A$ are reduced to $£ 0$. The initial earnings of the seven participants B are not reduced so that they start with $£ 10$ each. The participant assigned role A does not make any decisions in the experiment. Participants assigned role $\mathrm{B}$ are asked to make one decision each.

Each participant B decides whether to transfer money from his or her $£ 10$ to participant A. Participants B choose between two options:

- $\quad$ PASS - then no money is transferred to A, and B keeps his or her own $£ 10$.

- TRANSFER - then B has to decide an amount $T$, between $£ 1$ and $£ 10$, to transfer from his or her own $£ 10$ to A. 
Participants B make their decision on a computer screen similar to that shown below:

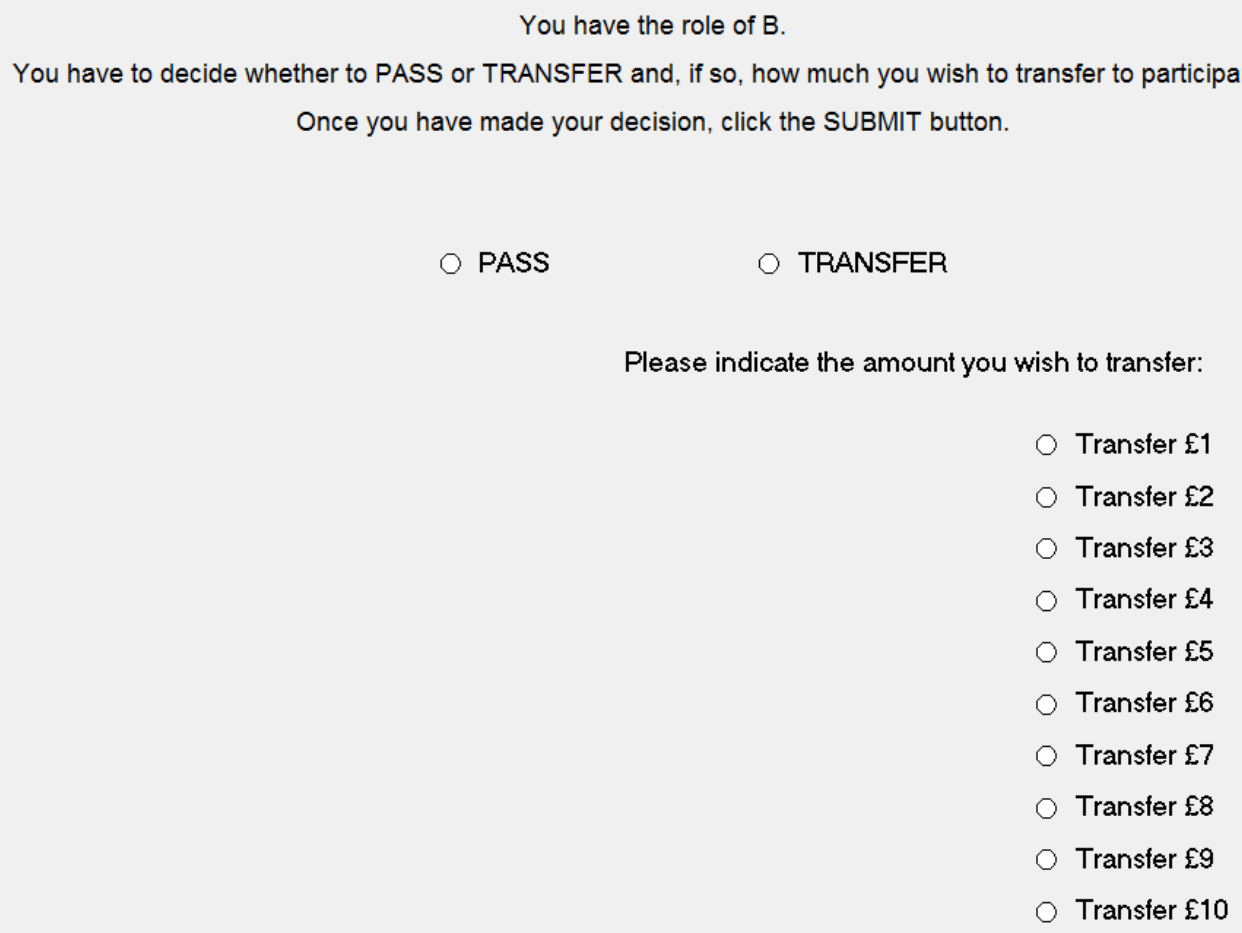

Although all seven participants B in the group make a decision, at most one participant B is matched with participant A and thereby has his or her decision implemented. At the end of the experiment the computer determines which (if any) of the seven participants B is matched with A using the following criterion:

- If a participant B has chosen to PASS, then he or she is not selected by the computer.

- If a participant B has chosen to TRANSFER, then he or she may be selected by the computer.

Therefore, based on the decisions of the seven participants $\mathrm{B}$, one of three possible situations arises:

- No participant B has chosen to TRANSFER (i.e., all participants B have chosen to PASS). Then no participant B is matched with A. The seven participants B earn $£ 10$ each and participant A earns $£ 0$.

- Only one participant B has chosen to TRANSFER. Then this participant B is matched with A. His or her monetary transfer is implemented. The selected participant B earns $£ 10$ - £T (the amount transferred). Participant A earns $£$ T. The other six participants B earn $£ 10$ each.

- More than one participants B have chosen to TRANSFER. Then one of these participants B is selected by the computer at random. His or her monetary transfer is implemented. The selected participant B earns $£ 10-£ T$. Participant A earns $£$ T. The other six participants B earn $£ 10$ each. 
So, to recap: participant A does not have a decision to make in the experiment. For participants B:

- Participants B are asked to choose whether to PASS or TRANSFER.

- If a participant B has chosen to TRANSFER and he or she is the only participant B who has chosen to TRANSFER, he or she is matched with participant A and participant A receives his or her monetary transfer.

- If a participant B has chosen to TRANSFER and he or she is not the only participant B who has chosen to TRANSFER, he or she is matched with participant A and participant A will receive his or her monetary transfer as long as he or she is randomly selected by the computer.

- If a participant B has chosen to PASS, he or she is not matched with participant A. Participant A receives a monetary transfer from one of the other six participants B as long as one of them has chosen to TRANSFER.

At the end of the experiment the computer informs all group members of the decisions made by the seven participants B in the group. The computer also informs all group members of which (if any) participant B has been selected, and the corresponding earnings of each group member.

This information is shown to each participant using a computer screen similar to that shown below.

\section{Outcome in your group:}

\begin{tabular}{|c||c||c||c|}
\hline Participant & Decision & Selected & Earnings \\
\hline A & - & - & $x x x$ \\
B & $x x x$ & $x x x$ & $x x x$ \\
B & $x x x$ & $x x x$ & $x x x$ \\
B & $x x x$ & $x x x$ & $x x x$ \\
B & $x x x$ & $x x x$ & $x x x$ \\
B & $x x x$ & $x x x$ & $x x x$ \\
B & $x x x$ & $x x x$ & $x x x$ \\
B & $x x x$ & $x x x$ & $x x x$ \\
\hline
\end{tabular}

The first column shows the role of each participant and the second column shows the decision made by each participant. The third column shows whether the participant has been selected by the computer and the fourth column shows each participant's earnings.

Thereafter, the experiment ends and all participants are paid their earnings in private and in cash. 
Before we continue with this experiment we want to check that each participant understands how the earnings in the situation described above would be calculated. To do this we ask you to answer the questions below. In a couple of minutes the experimenter will check your answers. When each participant has answered all questions correctly we will continue with this experiment.

If you have a question at any time, raise your hand and the experimenter will come to your desk to answer it.

\section{Questions About The Situation}

1) How many participants are asked to make a decision?

a) One participant B b) Two, participant A and one participant B

c) All seven participants B

2) How many participants at most are matched with participant $A$ ?
a) Seven
b) One
c) Zero

3) One of the following statements is false. Please indicate which one is false by putting an ' $\mathrm{X}$ ' next to it.

a) If six participants B decide to PASS and one participant B decides to TRANSFER $£ 4$, then this participant B is matched with A. A earns $£ 4$, the selected participant B earns $£ 6$ and the other six participants B earn $£ 10$ each.

b) If all participants B decide to PASS, then no participant B is matched with A. A earns $£ 0$ and the seven participants B earn $£ 10$ each.

c) If two participants B decide to TRANSFER and the other five decide to PASS, then one of the participants B who decided to PASS is matched with A. A earns $£ 6$, the selected participant B earns $£ 4$, and the six other participants B earn $£ 10$ each.

4) Suppose that in one group the participants B make their decisions as follows:

Participant B1: TRANSFER $£ 7$

Participant B2: PASS

Participant B3: TRANSFER $£ 2$

Participant B4: TRANSFER $£ 1$

Participant B5: PASS

Participant B6: TRANSFER $£ 10$

Participant B7: PASS

The computer randomly selects participant B3 to be matched with participant A. Please indicate the earnings of all participants in this group:

Participant A:

Participant B3:
Participant B1:

Participant B4:
Participant B2:

Participant B5: 
Participant B6:

Participant B7:

\section{Your task in today's experiment}

Your task in today's experiment is to evaluate the different possible actions available to one of the participants $B$ in the situation described above.

On your computer screen you will see a table where you must indicate, for each of the 11 possible actions available to the participant $\mathrm{B}$, whether you believe that choosing that action is very socially inappropriate, socially inappropriate, somewhat socially inappropriate, somewhat socially appropriate, socially appropriate, or very socially appropriate. Recall that by socially appropriate, we mean behaviour that you think most participants would agree is the "correct" thing to do. To indicate your response, please choose one option in each row.

At the end of the experiment, we will randomly select one of the possible actions that the participant B could have taken. If your evaluation matches the response of the other participant who is matched with you, you will receive $£ 8$, otherwise you will receive zero.

Please now look at your computer screen and indicate your responses. 


\section{Appendix C: Social Appropriateness Ratings}

Table C.1 presents the distribution of the social appropriateness ratings in the Control and Bystander treatments separately. The far-right column presents p-values of the Fisher's randomization tests for the comparison of the mean rating between the Control and Bystander treatments, for each of the actions.

Table C.1 Social appropriateness ratings

\begin{tabular}{|c|c|c|c|c|c|c|c|c|c|c|c|c|c|c|c|}
\hline Action & Mean & -- & -- & $\begin{array}{l}\text { Control } \\
(n=60)\end{array}$ & + & ++ & +++ & Mean & -- & -- & $\begin{array}{l}\text { ystande } \\
n=62)\end{array}$ & + & ++ & +++ & $\begin{array}{c}\text { Bystander vs } \\
\text { Control p- } \\
\text { value, } \\
\text { Fisher's } \\
\text { rand. test } \\
\end{array}$ \\
\hline No Transfer & -0.64 & $63 \%$ & $10 \%$ & $13 \%$ & $3 \%$ & $7 \%$ & $3 \%$ & -0.55 & $52 \%$ & $13 \%$ & $21 \%$ & $5 \%$ & $6 \%$ & $3 \%$ & 0.57 \\
\hline Transfer $£ 1$ & -0.27 & $17 \%$ & $38 \%$ & $10 \%$ & $20 \%$ & $12 \%$ & $3 \%$ & -0.15 & $8 \%$ & $34 \%$ & $19 \%$ & $19 \%$ & $15 \%$ & $5 \%$ & 0.39 \\
\hline Transfer $£ 2$ & -0.11 & $5 \%$ & $30 \%$ & $20 \%$ & $30 \%$ & $12 \%$ & $3 \%$ & -0.06 & $2 \%$ & $24 \%$ & $34 \%$ & $21 \%$ & $16 \%$ & $3 \%$ & 0.70 \\
\hline Transfer $£ 3$ & 0.15 & $2 \%$ & $3 \%$ & $33 \%$ & $35 \%$ & $22 \%$ & $5 \%$ & 0.18 & $0 \%$ & $5 \%$ & $27 \%$ & $39 \%$ & $26 \%$ & $3 \%$ & 0.75 \\
\hline Transfer $£ 4$ & 0.38 & $0 \%$ & $0 \%$ & $18 \%$ & $25 \%$ & $50 \%$ & $7 \%$ & 0.43 & $0 \%$ & $2 \%$ & $3 \%$ & $37 \%$ & $52 \%$ & $6 \%$ & 0.53 \\
\hline Transfer $£ 5$ & 0.73 & $0 \%$ & $0 \%$ & $2 \%$ & $8 \%$ & $45 \%$ & $45 \%$ & 0.75 & $0 \%$ & $0 \%$ & $3 \%$ & $6 \%$ & $39 \%$ & $52 \%$ & 0.76 \\
\hline Transfer £6 & 0.61 & $0 \%$ & $3 \%$ & $5 \%$ & $18 \%$ & $33 \%$ & $40 \%$ & 0.61 & $0 \%$ & $3 \%$ & $11 \%$ & $8 \%$ & $35 \%$ & $42 \%$ & 1.00 \\
\hline Transfer $£ 7$ & 0.61 & $0 \%$ & $5 \%$ & $10 \%$ & $8 \%$ & $32 \%$ & $45 \%$ & 0.54 & $0 \%$ & $8 \%$ & $11 \%$ & $16 \%$ & $18 \%$ & $47 \%$ & 0.58 \\
\hline Transfer $£ 8$ & 0.55 & $0 \%$ & $13 \%$ & $5 \%$ & $13 \%$ & $18 \%$ & $50 \%$ & 0.49 & $2 \%$ & $13 \%$ & $13 \%$ & $8 \%$ & $13 \%$ & $52 \%$ & 0.71 \\
\hline Transfer $£ 9$ & 0.51 & $7 \%$ & $8 \%$ & $7 \%$ & $12 \%$ & $12 \%$ & $55 \%$ & 0.45 & $6 \%$ & $15 \%$ & $6 \%$ & $8 \%$ & $11 \%$ & $53 \%$ & 0.73 \\
\hline Transfer $£ 10$ & 0.46 & $15 \%$ & $3 \%$ & $5 \%$ & $12 \%$ & $8 \%$ & $57 \%$ & 0.39 & $19 \%$ & $5 \%$ & $6 \%$ & $5 \%$ & $8 \%$ & $56 \%$ & 0.72 \\
\hline
\end{tabular}

Notes: The ratings, from very socially inappropriate to very socially appropriate, are indicated with "---“ to "+++". The rating that has been chosen by the largest percentage of subjects for each given action and for each given treatment is highlighted in grey. ***Significant at the 1 percent level. **Significant at the 5 percent level. *Significant at the 10 percent level. 